\title{
WestVirginiaUniversity
}

THE RESEARCH REPOSITORY @ WVU

Graduate Theses, Dissertations, and Problem Reports

2016

\section{Migratory Genomics of Lake Sturgeon}

Justine Whitaker

Follow this and additional works at: https://researchrepository.wvu.edu/etd

\section{Recommended Citation}

Whitaker, Justine, "Migratory Genomics of Lake Sturgeon" (2016). Graduate Theses, Dissertations, and Problem Reports. 6941.

https://researchrepository.wvu.edu/etd/6941

This Dissertation is protected by copyright and/or related rights. It has been brought to you by the The Research Repository @ WVU with permission from the rights-holder(s). You are free to use this Dissertation in any way that is permitted by the copyright and related rights legislation that applies to your use. For other uses you must obtain permission from the rights-holder(s) directly, unless additional rights are indicated by a Creative Commons license in the record and/ or on the work itself. This Dissertation has been accepted for inclusion in WVU Graduate Theses, Dissertations, and Problem Reports collection by an authorized administrator of The Research Repository @ WVU.

For more information, please contact researchrepository@mail.wvu.edu. 


\title{
Migratory Genomics of Lake Sturgeon
}

\author{
Justine Whitaker
}

\begin{abstract}
A Dissertation submitted to
The Davis College of Agriculture, Natural Resources and Design at West Virginia University

in partial fulfillment of the requirements for the degree of

Doctor of Philosophy

in Forest Resources Science
\end{abstract}

Amy Welsh, Ph.D., Chair

James Boase, M.Sc.

Timothy King, Ph.D.

Patricia Mazik, Ph.D.

Stuart Welsh, Ph.D.

Wildlife and Fisheries Resources

Department of Forestry and Natural Resources

\section{Morgantown, West Virginia}

2016

Keywords: conservation genetics, lake sturgeon, migratory genomics, migration, genetic diversity, St.

Clair-Detroit River System

Copyright 2016 Justine Whitaker 


\section{ABSTRACT \\ Migratory Genomics of Lake Sturgeon}

Justine Whitaker

Lake sturgeon are large, freshwater fish and the only species of sturgeon native to the Great Lakes. Their historic range extends from the Hudson Bay, down through the Great Lakes and into the Mississippi River basin. In the early 1900's, sturgeon became a valuable fishery and were soon overfished for both meat and caviar. This, in combination with damming, pollution, and habitat degradation, caused a drastic decline in their population. Some populations were extirpated, while others have been reduced to $1 \%$ of their historic population size (Auer, 1996). The St. Clair-Detroit River System (SCDRS) hosts one of the largest lake sturgeon populations in the Great Lakes, despite habitat degradation. This system has no dams and provides an excellent study site to understand both population structure and the movements of an unimpeded population. The lake sturgeon in the SCDRS appear to have fine-scale genetic structure. Lake sturgeon were grouped according to sampling location (upper St. Clair, lower St. Clair, and Detroit Rivers). Bayesian analysis, implemented by the program STRUCTURE, revealed that there are two clusters $(K=2)$ within the SCDRS. The $F_{S T}$ values calculated for the sampling locations showed that the upper St. Clair River is genetically differentiated from the lower St. Clair River $\left(F_{S T}=0.0135, \mathrm{p}=0.02\right)$. Additionally, results from the discriminant analysis of principal components showed moderate clustering of the sampling locations. Lake sturgeon in the SCDRS exhibit partial migration with some individuals migrating from lakes to rivers and others inhabiting the rivers year-round. An integrative approach employing morphometrics, genetic and epigenetic techniques was used to characterize the migratory phenotypes. Based on telemetry data, fish were grouped according to migratory phenotype and then analyzed for differences in morphometrics, genetics, and epigenetics. The principal components analysis, performed on 18 morphological features, did not support the hypothesis that there are morphological differences between lake sturgeon ( $\mathrm{n}=63 ; 38$ residents, 27 migrants). To identify a genetic component to the variation in migratory phenotypes, a subset of those samples $(n=41 ; 19$ residents, 22 migrants) were analyzed at 11 microsatellite loci. Bayesian analysis revealed that there is one population, indicating gene flow between the migratory phenotypes. The $F_{S T}$ value calculated to determine genetic differentiation between migratory phenotypes was 0.0148 $(\mathrm{p}=0.11)$, which is interpreted as no genetic differentiation between the two groups. DNA extractions from blood samples were analyzed using the methylation sensitive amplified fragment length polymorphism (MS-AFLP) protocol to test for epigenetic differences. The AMOVA performed on all restriction sites (81) showed that the migratory phenotypes are differentially methylated $(\mathrm{p} \leq 0.05)$. The AMOVA performed on individual restriction sites showed that 13 were differentially methylated. Using BayeScan, restriction sites were tested for deviation from a neutral model of selection, and none of these sites were determined to be under selection. While there is no evidence for a genetic component to the migratory phenotypes of lake sturgeon in the SCDRS, DNA methylation may play a role in the observed plasticity of movement patterns. 
Table of Contents

Section

Page

ABSTRACT II

CHAPTER 1: LITERATURE REVIEW AND OBJECTIVES 1

LAKE STURGEON NATURAL HISTORY

TAXONOMY

MORPHOLOGY AND FEEDING

MANAGEMENT

GENETICS

SPAWNING AND MOVEMENT

EPIGENETICS

STUDY SITE

REFERENCES

(1)

(1)

CHAPTER 2: GENETIC STRUCTURE OF LAKE STURGEON IN THE ST. CLAIR-DETROIT \begin{tabular}{ll} 
RIVER SYSTEM & 26 \\
\hline
\end{tabular}

INTRODUCTION

$\begin{array}{ll}\text { METHODS } & 28\end{array}$

$\begin{array}{lr}\text { STUDY SITE } & 28\end{array}$

SAMPLING

LABORATORY TECHNIQUES

POPULATION CLUSTERING AND GENETIC DIFFERENTIATION

ASSIGNMENT OF POTENTIAL MIGRANTS

RESULTS

POPULATION CLUSTERING AND GENETIC DIFFERENTIATION

ASSIGNMENT OF POTENTIAL MIGRANTS

DISCUSSION

$\begin{array}{ll}\text { REFERENCES } & 37\end{array}$

CHAPTER 3. CHARACTERIZING THE MIGRATORY PHENOTYPE OF LAKE STURGEON 47

INTRODUCTION

MATERIALS AND METHODS

STUDY SITE

STURGEON CAPTURE AND TAGGING

ACOUSTIC MONITORING NETWORK AND ACOUSTIC DATA FILTERING

MORPHOMETRICS

GENETIC DIFFERENTIATION

STATISTICAL ANALYSIS $\quad 56$

DIFFERENTIAL METHYLATION

STATISTICAL ANALYSIS

$\begin{array}{ll}\text { RESULTS } & 58\end{array}$

MORPHOMETRICS

GENETIC DIFFERENTIATION

DIFFERENTIAL METHYLATION 
DISCUSSION

REFERENCES 


\section{Acknowledgements}

I would like to acknowledge Darryl Hondorp and Charles Krueger with the US Geological Survey, Great Lakes Science Center whom assisted in providing samples, photography, and telemetry data; Justin Chiotti, Andrew Briggs, Margaret Hutton and Jeremy Moore with the US Fish and Wildlife Service; Karen Soper and Chris Gignac with the Ontario Ministry of Natural Resources and Forestry; Jennifer Smith with the University of Windsor; Mike Thomas with Michigan Department of Natural Resources; and the staff of the Michigan Department of Natural Resources-Lake St. Clair Fisheries Research Station for assistance with fish sampling. I would also like to thank George Merovich for his assistance with analysis. This work was funded by National Institute of Food and Agriculture, U.S. Department of Agriculture, Hatch Project WVA00637.0227396 and the West Virginia University Provost Doctoral Fellowship. Lastly, I would like to thank my lab-mates in the Wild Genomics lab and my friends and family for continued support throughout this project. 


\section{Chapter 1: Literature Review and Objectives}

\section{Lake Sturgeon Natural History}

Lake sturgeon are large, freshwater fish and the only species of sturgeon native to the Great Lakes. They can grow as long as 2 meters, and may weigh as much as 90 kilograms (Harkness and Dymond, 1961). Their historic range extends from the Hudson Bay, down through the Great Lakes and into the Mississippi River basin, and is one of the most widely distributed freshwater fish in North America (Harkness and Dymond, 1961). Lake sturgeon were originally considered by-catch and were not considered a valuable fishery. Their bodies were hauled to shore, piled up, and burned (Harkness and Dymond, 1961). In the early 1900's, sturgeon became a valuable fishery and were soon overfished for both meat and caviar. This in combination with damming, pollution, and habitat degradation caused a drastic decline in their population. Some populations were extirpated, while others have been reduced to $1 \%$ of their historic population size (Auer, 1996).

\section{Taxonomy}

There are approximately 27 living species of Acipenseriformes, including 25 species of sturgeon (Acipenseridae) and two paddlefish (Polyodontidae). Acipenseridae includes the genera of Acipenser, Huso, Scaphirynchus and Pseudoscaphirhynchus. Acipenser contains over 20 species that can be grouped geographically, including the Ponto-Caspian, China-Western America, Atlantic, and the eastern-North America (Birstein, 1993). Within North America, there are eight species of sturgeon, including the shortnose sturgeon (A. brevirostrum), green sturgeon (A. medirostris), Atlantic sturgeon (A. oxyrinchus oxyrinchus; subspecies: Gulf sturgeon ( $A$. oxyrinchus desotoi)), white sturgeon (A. transmontanus), pallid sturgeon (Scaphirhyncus albus), 
shovelnose sturgeon (S. platorynnchus), Alabama shovelnose sturgeon (S. suttkusi), and the lake sturgeon (A. fulvescens).

The phylogenetic relationships of species of sturgeon are debatable, depending on the methods of developing the phylogenies. Early attempts were made using morphometrics, but more recent phylogenies built on molecular data does not support those earlier trees. Using three regions of the cytochrome $\mathrm{b}$ and fragments of both the $12 \mathrm{~S}$ and $16 \mathrm{~S}$ ribosomal RNA genes, trees were created for all living species of Acipenseridae (Birstein and DeSalle, 1998). Based on these phylogenies, created through maximum parsimony, three clades of Acipenser were identified: an A.sturio-A.oxyrinchus clade, an A.schrenkii-A.brevirostrum clade, and a clade that includes all of the Ponto-Caspian species. Lake sturgeon were found to be distantly related to shortnose sturgeon (A. brevirostrum) since lake sturgeon are the sister species of all other Acipenser species with the exception of the A.sturio-A.oxyrinchus clade, but shortnose sturgeon falls within the Ponto-Caspian group. This is somewhat surprising since both are North American species, and it was thought they were likely closely related due to geographic proximity. Lake sturgeon may instead be a descendant of an ancient group of sturgeon that are basal to all other species. However, the placement of lake sturgeon within these trees was not as well supported as that of the other Acipenser species (Birstein and DeSalle, 1998).

Krieger et al. (2007) produced updated Acipensiformes species designations using additional sequence data. Maximum likelihood, Bayesian, and neighbor-joining trees were created based on cytochrome b, 12S rRNA, cytochrome c oxidase subunit II, tRNAPhe, tRNAAsp, 16S rRNA, NADH5 and control region sequences. These methods revealed that Atlantic sturgeon (A.oxyrinchus) may be basal to other species of North American sturgeon. North American species appeared to be divided geographically: lake sturgeon and shortnose 
sturgeon appeared to be sister-species and form an eastern group; the white sturgeon ( $A$.

transmontanus) and the green sturgeon (A. medirostris) are also sister-species that form the western group. The two subspecies of the Atlantic sturgeon for the third group. The results regarding the relationship between lake sturgeon and shortnose sturgeon conflict with the study performed by Birstein and DeSalle (1998), but agree with the results of Artyukhin (1995), which were based on morphological methodologies.

\section{Morphology and Feeding}

Sturgeon evolved approximately 200 million years ago and retain many primitive characteristics possessed by ancient ancestors. This includes a scaleless body protected by five rows of plates called scutes. As juveniles, the scutes are sharp, with a spur at the tip. The scutes are gradually resorbed over time (Vecsei and Peterson, 2004) and may even fall off (Harkness and Dymond, 1961). Lake sturgeon also have a heterocercal, shark-like tail. Unlike modern fish, lake sturgeon have a large swim-bladder that maintains some of the characteristics showing that it evolved from a lung in ancient fish (Harkness and Dymond,1961).

All sturgeon possess a ventrally flattened rostrum with sensory barbels used to detect prey, making them highly adept at benthic feeding. Their jaws are ventrally protruding, toothless and capable of creating suction. Lake sturgeon eat insects, insect larvae, mollusks, crustaceans, small fish, and more rarely, worms and fish eggs (Miller, 2004). Diet composition depends largely upon food availability (Harkness and Dymond, 1961; Scott and Crossman, 1973), which is dependent upon substrate (Chiasson et al., 1997; Harkness and Dymond, 1961). Their benthic behavior combined with their long lifespan may make them good indicators of the health of a system because they are susceptible to bioaccumulation of pollutants (DiVincenti et al., 2013). 
As benthic feeders, lake sturgeon inhabit the bottom of water bodies, and substrate may ultimately dictate the movement of lake sturgeon. Predominately inhabiting shallow waters of 927 meters, some sturgeon have been documented at depths of up to 43 meters (Harkness and Dymond, 1961) and prefer shoal waters that are highly productive (Scott and Crossman, 1973). Habitat choice and water depth is thought to be dependent upon where favorable prey are found (Boase et al., 2011; Chiasson et al., 1997; Rusak and Mosindy, 1997).

Morphological variations within species of sturgeon is common, and may include differences in rostrum shape, head width, and mouth size (Vecsei and Peterson, 2004). Observations of morphology led to the suggestion of different populations of lake sturgeon, based on variations in morphology. In most populations of lake sturgeon, intermediates have been found, discounting the suggestion of two morphologies of lake sturgeon (Harkness and Dymond, 1961). Also complicating the study of intraspecific morphological variation is that morphological differences can vary ontogenetically and phylogenetically (Vecsei and Peterson, 2004). However, more recent studies have shown that there may be some cases where varying habitats or life histories may lead to morphologically distinct populations. Morphometrics and meristics have been used to distinguish populations within and between species, as well as hybridization between species (Bakhshalizadeh et al., 2013; Costa et al., 2006; Guenette et al., 1992; North et al., 2002 ; Vasil'eva, 2009; Walsh et al., 2001; Wills et al., 2002). In Quebec, two morphologies of lake sturgeon were identified by Roussow (1955): one with a small head and tapered rostrum, and another with a rounded rostrum and larger head. Lake sturgeon have been shown to vary morphometrically when living in different river systems (Ruban and Sokolov, 1987) and in different branches within the same river (Guenette et al., 1992); those differences can be attributed to subtle environmental variation, such as water temperature or current velocity 
(Ruban and Sokolov, 1986). Guenette et al. (1992) showed that the more sedentary population of lake sturgeon in Lac des Deux Montagnes was morphologically distinct from other populations of lake sturgeon in the St. Lawrence River.

\section{Management}

The protection afforded to lake sturgeon varies by country, province, and state. Lake sturgeon are not federally protected in the United States, but its listing under Appendix II on the Convention on International Trade of Endangered Species was reinstated in 1998 (Peterson et al., 2007). Under Appendix II, trade of species is closely controlled to ensure that they do not become threatened with extinction, and it is therefore necessary to obtain a permit to trade specimens. According to the United Nations Environmental Programme, the lake sturgeon is now listed as "vulnerable" internationally; however, its status differs by population, and within some US states, it is considered "threatened" (Auer, 2004). Around the early 1900s, overharvest of lake sturgeon for flesh and roe resulted in a population decline in both the Great Lakes and Canada. Fisheries were closed in the 1920s, but pollution, habitat degradation, dams and barriers continue to threaten populations. Sturgeon life history characteristics, such as late maturation and spawning periodicity, potentially make them more vulnerable to anthropogenic pressures

(Peterson et al., 2007). Although lake sturgeon have not been afforded federal protection under the Endangered Species Act, many states provide protection. In Illlinois, Indiana, Ohio, and Pennsylvannia, they are considered endangered, while Michigan and New York deem them as threatened, and in Minnesota, they are considered a species of special concern (Welsh 2004).

Despite improved conditions, some lake sturgeon populations are not showing signs of recovery while others are only recovering slowly (Pollack et al., 2014). Most management plans 
for sturgeon species include potential solutions to impediments such as overharvest, dams that impede migration, and habitat loss or degradation (Auer, 2004; Ferguson and Duckworth, 1997; Hay-Chmielewski and Whelan, 1997). In many cases, low population levels and habitat loss are listed as important issues to overcome in the recovery of sturgeon (Auer, 2004). Additionally, managing a species that lives and moves across state and country boundaries can be complex. This can result in a variety of management plans that possibly conflict regarding the best management practices. There are examples of successful management despite multijurisdictional issues, such as the cooperative effort shown in the implementation of the sea lamprey control plan where control of the sea lamprey could have had a negative impact on lake sturgeon management (Auer, 2004).

The primary methods for managing sturgeon populations are fishery control/closure, and artificial propagation/stocking. After the drastic decline in population, many fisheries were closed. Some remained open, but catch was reduced. For instance, in the St. Lawrence River, the commercial catch was reduced by $60 \%$ and a system implemented to ensure that the catch reduction was adhered to (Mailhot et al., 2011). Artificial propagation of lake sturgeon has posed some difficulties because they do not adjust well to captivity, primarily with respect to feeding (Bardi et al., 1998). They are usually fed natural foods (e.g. brine shrimp, blood worms) instead of a formulated feed (Klassen and Peake, 2008). Reluctance to feeding in captivity may contribute to increased mortality in hatcheries, as well as reduced health and size (Klassen and Peake, 2008).

Stocking is also an important factor of lake sturgeon management. New York, Wisconsin and Michigan actively stock lake sturgeon populations, including eggs, larvae, fingerlings and adults. Hatcheries are employed, as well as head-start, streamside facilities used to take juvenile 
fish from the wild, rear them, and then release them a few months later (Welsh et al., 2010). Genetics has become an important factor in determining how stocking should be performed. Through a genetic assessment of the Great Lakes lake sturgeon populations, Welsh et al. (2010) established guidelines for assessing the appropriateness of donors for stocking populations. These guidelines include: reducing the risk of outbreeding depression, having an understanding of gene flow between populations, and geographically close populations may provide suitable donors for stocking when genetic data are unknown.

\section{Genetics}

Genetic studies can be important for establishing the ancestry of populations, the demographic history, appropriate management units, and possibly even their adaptive potential (DiBattista, 2008; Latta, 2008; Stockwell et al., 2003). Genetic studies of lake sturgeon have predominately focused on microsatellites and mitochondrial DNA (mtDNA). Using different markers can be beneficial to a full understanding because they provide different insights. For instance, mtDNA is useful for understanding historical population patterns, while microsatellites are useful for understanding more contemporary structure.

Genetic assessments are being performed to determine whether lake and river systems host a single population or multiple, reproductively isolated populations. Great Lakes-wide population structure analyses using neutral markers have been performed to show that lake sturgeon populations are genetically diverse throughout the distribution (DeHaan, 2008; McDermid et al., 2011; Welsh et al., 2008). Based on genotyping of 22 lake sturgeon spawning populations at 12 microsatellite loci, Lake Superior had more genetic diversity than those in the remainder of the Great Lakes (Welsh et al., 2008). Those 22 spawning populations were grouped 
into six Genetic Stocking Units (GSUs) (Welsh et al., 2010). In some cases, it has been found that despite rapids, which could represent natural barriers, an entire river system may be inhabited by a single population (Welsh and McLeod, 2010; Wozney et al., 2011). More data are necessary to determine if some populations may be divided into subpopulations within one system due to various reasons, including fragmentation and habitat use. With the advent of new sequencing technology, single-nucleotide polymorphisms (SNPs) and whole genome sequencing is becoming more common. SNPs may eventually provide a more refined analysis of population structure of lake sturgeon because they are found throughout the genome and can be used to identify both neutral and adaptive variation (Ogden et al., 2013).

In addition to geography and anthropogenic impacts, genetic differentiation can be caused by historical events. Understanding the ancestry of populations can be important for lake sturgeon because their current genetic structure may be influenced by their phylogeographic history, during which they were displaced and then recolonized the Great Lakes (Bernatchez and Wilson, 1998; Mandrak and Crossman, 1992). About 8,000-10,000 years ago, during the Wisconsinian glacial period, the Hudson Bay and Great Lakes were covered in ice. Many of the freshwater species that survived migrated to southern refugia, primarily the Mississipian refugium. As the glacier receded, the area was recolonized by species from southern drainages (Layeghifard et al., 2012; Mandrak and Crossman, 1992). Based on mitochondrial markers, the populations that recolonized the Hudson Bay appear to be genetically distinct from those in the Great Lakes, possibly due to recolonization from different refugia (Ferguson, 1997). Using 14 microsatellites, 23 populations in northern Ontario were clustered into three groups, presumably corresponding to one novel group, and the two refugia, Mississippian and Missourian (McDermid et al., 2011). 
Karyotype and genetic studies of sturgeon have revealed that at least $50 \%$ of sturgeon species are polyploid (have more than two copies of each allele in their genomes), falling into three categories: 120, 240, and 500 chromosomes (Birstein, 1993). The corresponding ploidy levels for those chromosome categories are controversial, but some researchers propose a 4n, 8 n, 16n relationship (Birstein and Vasiliev, 1987; Birstein, 1993; Blacklidge and Bidwell, 1993). Lake sturgeon are considered tetraploids, which can make genetic analyses more complicated. However, one study has shown that it is possible to successfully characterize a transcriptome of lake sturgeon. Hale et al (2009) used next generation sequencing (NGS) to characterize gonad transcriptomes, showing that non-model, polyploid species are candidates for NGS studies. When working with polyploid species, SNPs is becoming the marker of choice because it is easier to sort out copy number and codominance with this marker (Ogden et al., 2013).

Spawning and Movement

Lake sturgeon are long-lived and mature late (12-15 years in males, 18-27 years in females) (Scott and Crossman, 1973). They live predominately in freshwater, but tolerate salinities of around 15ppt (Harkness and Dymond, 1961). Spawning is intermittent, occurring every 4-9 years for females and every 1-4 years for males in the spring, typically on rocky substrate in fast flowing water (Fortin et al., 1996). This may vary by watershed and advances in telemetry are allowing researchers to provide detailed information on spawning periodicity. In the spring (May-June), adults usually migrate from lakes to spawning sites in rivers, and return once spawning has concluded (Peterson et al., 2007). Spawning is usually initiated when the water temperature reaches approximately $13^{\circ} \mathrm{C}-18^{\circ} \mathrm{C}$ (Harkness and Dymond, 1961; LaHaye et al., 1992; Scott and Crossman, 1973), but this will vary by location. For instance, they will 
usually spend the remainder of the summer in the lakes feeding (Harkness and Dymond, 1961). In late fall, they will often locate an overwintering site, such as a deep well near the mouth of a river and spend most of the winter there (Harkness and Dymond, 1961).

Lake sturgeon migration distances are not fully understood. Movements have been recorded as ranging from $32 \mathrm{~km}$ (Shively and Kmiecik, 1989) to $225 \mathrm{~km}$ (Fortin et al. 1993), and they show signs of returning to the same spawning grounds each year (Dadswell, 1979; Lyons and Kempinger, 1992). Dams and other barriers now block migratory routes of some populations of sturgeon, confining populations, possibly reducing their fitness and reproductive success. Females may even resorb eggs if they meet a barrier (Veshchev and Novikova, 1983). In areas of dams, eggs have been spawned in large masses, which is not characteristic of sturgeon behavior when not impeded by a barrier. Eggs are usually observed under rocks in groups of fewer than 20 eggs (Auer, 1996). Some populations have been extirpated by barriers (Aadland et al., 2005). These barriers prevent migration, confining populations and preventing gene flow, which can affect the ability of the species to adapt to future environmental changes, such as climate change.

Migration of lake sturgeon to spawning grounds varies by population. In most populations of the Great Lakes, lake sturgeon return to the lake after spawning in the rivers. However, in some populations, such as the St. Clair River, both migration and river residency (i.e. partial migration) have been recorded in the same population. Alternatively, some entire populations, such as those that reside in the Hudson Bay system, are primarily river residents that do not migrate. According to a study by Rusak and Mosindy (1997), in the Lake of the Woods and the Rainy River, Ontario lake sturgeon appear to be differentiated into two groups: the "lake" population and the "river" population. During the study, the lake population primarily used the lakes, moving into the rivers to spawn and rare feeding opportunities in the summer. 
The river fish remained in the Rainy River for the majority of the multi-year study. These two populations may be genetically distinct and management of the lake-river system should reflect the differences in populations. Rusak and Mosindy (1997) cautions against managing sturgeon in lake-river systems as one population when in fact varying habitats may cause differentiation into separate populations.

Beyond migration, lake sturgeon tend to be fairly sedentary (Scott and Crossman, 1973). Studies of non-migratory movements of lake sturgeon have shown that across their distribution, fish can often be recaptured within $5 \mathrm{~km}$ of their original capture site (Fortin et al., 1993; Threader and Brousseau, 1986; Thuemler, 1997;). However, in some cases, fish in these studies traveled up to $225 \mathrm{~km}$ (Auer, 2004), showing the high variation in movement strategies, which requires further study to fully understand.

\section{Migratory Genomics \& Epigenetics}

Migration is a critical adaptation that is paramount to the survival of many species, yet the genomics involved in the traits required for the varying degrees of movement are largely unknown. Movement can be broken down into three main phenotypes: dispersal, migration, and station-keeping (Liedvogel et al., 2011). Dispersal is movement away from a population without a return trip. Migration is movement between two locations, requiring a spatiotemporal orientation so that the animal may return. Station-keeping (i.e. residency) is the non-migratory phenotype. Studies in genomics of populations exhibiting these phenotypes would not only reveal information regarding the behavior of migration, but may lead to understanding other life history characteristics, such as reproduction, that may be intertwined (Liedvogel et al., 2011). A 
full understanding of movement requires a multi-faceted approach that may include genetics, telemetry, and habitat metrics.

Effective migration, defined as movement between two locations for the purpose of breeding or spawning, is important for establishing gene flow within and across populations. Effective migration is a key component in the addition of genetic variation into a population. If gene flow is impaired, by a natural barrier or anthropogenic cause, populations may become reproductively isolated. This is especially relevant in fisheries due to dams, which can fragment fish populations (McDermid et al., 2014; Rosenberg et al., 2000; Strayer and Dudgeon, 2010). These subpopulations become genetically distinct, with lower genetic variability, leading to a lower evolutionary potential to adapt to change. If the isolated populations are small, inbreeding may occur, possibly leading to inbreeding depression, and a reduced adaptive fitness of the population.

A variety of species, including zooplankton, insects, fish, and turtles exhibit migration phenotypes, but it is most commonly studied in birds. Reports show that both migration and residency can be found within the same avian population (Dingle, 1996) and is known as 'partial migration' (Chapman, 2011). According to avian studies, this dimorphism may be a result of differences in the genome, the ability of an individual to acclimate, or learned behavior (Pigliucci, 2001). Currently, genetic evidence is lacking, and some propose that the impacts from a hostile environment may be a contributing factor in determining the migratory phenotype (Ogonowski and Conway, 2009). However, Pulido (2011) proposed the theory of a genetic "switch" that is employed at a particular threshold, causing the animal to migrate. If that threshold is not reached, the animal remains a resident (Pulido, 2011). 
Partial migration is widespread among fish, but has been studied primarily in salmonids using telemetry (Chapman, 2012). Some studies of fish are showing evidence for a genetic component of migration. Chinook salmon (Oncorynchus tshawytscha) show temporal variations in migration between populations. O'Malley et al. (2007) showed that a well characterized gene known as the Clock gene may influence migration and spawning times. The Clock gene has been well preserved across species, occurring in insects, mammals and fish, and regulates the expression of Period and Cryptochrome, two circadian rhythm genes. O'Malley et al. (2007) also identified another candidate gene, Ots515NWFSC, as being possibly involved in the timing of migration. Another study performed on pink salmon (Oncorynchus gorbuscha) revealed that the selective pressure of global climate change has caused microevolution of the timing of migration. Late migrating individuals were genetically marked with a known, neutral marker. Samples were then taken from the population over the course of 17 generations to identify the frequency of that genetic marker. Late migrating, genetically marked pink salmon were selected against in that relatively short period of time (32 years, 17 generations), resulting in a drop of frequency of the individuals carrying that genetic marker from 27-39\% in 1989 to 5\% in 2011 (Kovach et al., 2012). Both of these studies provide evidence that the timing of migration may be dependent upon gene expression, and may vary between populations of salmon.

Brook trout (Salvelinus fontinalis) is another species that demonstrates partial migration. Some individuals are anadromous, migrating to saltwater habitats for growth and returning to freshwater habitat for spawning, while others are considered residents and do not migrate. Characterization of the transcriptomes of gill tissue of anadromous individuals showed that expression of genes controlling metabolic activities differed from that of resident individuals (Boulet, 2012). These data show possible molecular adaptations associated with migration. 


\section{Epigenetics}

In addition to genomic regulation, migratory phenotypes may be a result of phenotypic plasticity, or the change in a phenotype in response to changing environmental conditions.

A plastic phenotype would allow an individual to alter a phenotype that is most beneficial based on environmental cues, or it might cause an individual to skip a year based on internal physiological cues. Phenotypic plasticity may be regulated by epigenetics. Epigenetics are changes in gene expression, as opposed to changes to the genes. Epigenetics have recently been recognized as an important part of the study of ecology since these markers may be an important evolutionary component. Some epigenetic markers are heritable and can be passed on to offspring (Jablonka, 2012), but epigenetic markers also provide an opportunity for an individual to respond to its environment on a shorter time scale (Angers et al., 2010). This may allow adaptation to an environment that is undergoing rapid change without having to rely on genetic changes acting on a long, evolutionary time scale.

The most widely used method of epigenetics in ecology studies are methylation assays (Bossdorf et al., 2008). The primary methods for measuring methylation in the genome of nonmodel organisms are methylation sensitive amplified fragment length polymorphism (MSAFLP) and bisulfite sequencing (BS-Seq). MS-AFLP is a method of measuring methylation by incorporating methylation sensitive restriction enzymes into the standard AFLP protocol, the result being a set of amplified fragments that can be visualized on a polyacrylamide gel. MSAFLP allows for a genome wide approach while bisulfite sequencing has been primarily used in targeting specific sequences, such as the promoter region of a gene. Treating DNA with bisulphite causes cytosine to be converted to uracil. If a cytosine base is methylated, it is not 
affected by bisulphite. Therefore, when sequenced, all methylated cytosines will be differentiated from un-methylated cytosines, which have been converted and sequenced as uracils. BS-Seq has been modified to allow for whole-genome sequencing that provides base resolution of methylation patterns. In combination, these methods have advanced the field of ecological epigenetics (Herrara and Bazaga, 2011; Massicotte et al., 2011; Schrey et al., 2012). Fish species living in cold waters near Antarctica showed significantly lower methylation than species living in tropical or temperate environments (Varriale and Bernardi, 2006), highlighting a link between environmental conditions and epigenetics. Epigenetic studies performed on wild vertebrates are rare due to logistics of ecological studies. Linking these differences in methylation to variation in phenotypes is the next step in understanding the role of epigenetics in the evolution of wild populations.

An alteration in methylation could be the result of a changing environment or a possible method of acclimating to a new environmental cue. It is not currently possible to discern between these two. Both types of cues could spur a cascade of molecular events leading to epigenetic mechanisms altering transcription of relevant proteins involved in the most beneficial migratory phenotype. Studies on Oncorhynchus mykiss have shown that differential methylation may be the means of creating phenotypic plasticity in complex morphological traits related to migration (Baerwald et al., 2015).

Identifying the degree of methylation may also infer the time scale of the phenotypes. In a varying environment, maintaining phenotypic plasticity is preferable compared to a change in the genome, which would require a long period of time and would be irreversible. Alternative phenotypes may be the result of phenotypic plasticity in the form of varying methylation patterns. These changes have been associated with variations in behavior, morphology, and 
physiology (Anway et al., 2005; Jeon, 2008; Weaver et al., 2004), the types of traits we expect to see altered with migratory phenotype. Understanding how a genome functions to create a complex phenotype, such as the migratory phenotype, is possible through gaining a better understanding of the epigenome.

\section{Study Site}

The St. Clair-Detroit River System (SCDRS) (Figure 1.1), a part of the Great Lakes system, consists of two major lakes and a river corridor connecting them. The St. Clair River, is 64 kilometers long, connecting Lake Huron and Lake St. Clair. Depths in the river range from 921 meters and velocities vary, with the highest velocity occurring around the International Blue Water Bridge. The bottom substrate of the St. Clair River is sand, silt and clay. The Detroit River, which is 45 kilometers long, connects Lake St. Clair with Lake Erie. The Detroit River is shallower, with depths reaching 16 meters. Both rivers combined form an important shipping channel connecting the upper and lower Great Lakes. Sediment removal, as much as 46 million $\mathrm{m}^{3}$ from the Detroit River (Bennion and Manny, 2011), and shipping channel construction has contributed to the degradation of the fish habitat within the SCDRS (Bennion and Manny, 2011). The St. Clair River and Detroit River are heavily developed, hosting industry and urban communities, both of which contribute to the determination that the system is an Area of Concern due to high levels of pollution (Bennion and Manny, 2011). There are no dams within this system and lake sturgeon are found throughout the SCDRS (Boase et al., 2011). The SCDRS hosts one of the largest lake sturgeon populations in the Great Lakes, despite habitat degradation. This site provides an excellent study site to understand both population structure and the movements of an unimpeded population. According to the analysis of 12 microsatellite loci 
performed on 22 Great Lakes lake sturgeon populations, the St. Clair and Detroit rivers are not genetically distinct (Welsh et al., 2008).

\section{Goals and Objectives}

The two goals of this project were to determine the population structure and to characterize the migratory phenotypes of lake sturgeon in the St. Clair-Detroit River System (SCDRS). To determine the population structure, we tested the hypothesis that the SCDRS was a panmictic population by refining the analysis using locations derived from telemetry data. To characterize the migratory phenotype, our objectives were to: 1) determine whether the lake sturgeon of the St. Clair system differ morphometrically due to variation in migratory phenotypes, 2) determine if individuals with different migratory phenotypes are reproductively isolated, and 3) determine if migratory and river resident individuals are differentially methylated, indicating epigenetic differences between the two phenotypes. 


\section{References}

Aadland, LP, TM Koel, WG Franzin. 2005. Changes in fish assemblage structure of the Red River of the North. Meeting: Symposium on Changes in Fish Community Structures in Large USA Rivers.

Angers, B, E Castonguay, and R Massicotte. 2010. Environmentally induced phenotypes and DNA methylation: how to deal with undrpredictable conditions until the next generation and after. Molecular Ecology. 19: 1283-1295.

Anway, MD, AS Cupp, M Uzumcu, MK Skinner. 2005. Epigenetic transgenerational actions of endocrine distrupters and male fertility. Science. 308: 1466-1469.

Auer, N. 1996. Importance of habitat and migration to sturgeons with emphasis on lake sturgeon. Canadian Journal of Fisheries and Aquatic Science. 53(1):152-160.

Auer, N. 2004. The Sturgeons and Paddlefish of America. Chapter 12. Pgs: 252-276.

Artyukhin, EN. 2006. Morphological phylogeny of the order Acipenseriformes. Journal of Applied Ichthyology. 22(1): 66-69.

Baerwald, MR, MH Meek, MR Stephens, RP Nagarajan, AM Goodbla, KMH Tomalty, GH Thorgaard, B May, KM Nichols. 2015. Special Issue: Epigenetic studies in ecology and evolution. Migration-related phenotypic divergence is associated with epigenetic modifications in rainbow trout. Molecular Ecology. doi: 10.1111/mec.13231.

Bakhshalizadeh, S, A Bani, and S Abdolmalaki. 2013. Comparative morphology of the pectoral fin spine of the Persian sturgeon Acipenser persicus, the Russian sturgeon (Acipenser gueldenstaedtii, and the Starry sturgeon Acipenser stellatus in Iranian waters of the Caspian Sea. Acta Zoologica. 94: 471-477. doi:10.1111/j.14636395.2012.00576.x.

Bardi, RW, Jr., FA Chapman, FT Barrows. 1998. Feeding trials with hatchery-produced Gulf of Mexico sturgeon larvae. Progressive Fish-culturist. 60: 25-31.

Bennion, DH, and Manny, BA. 2011. Construction of shipping channels in the Detroit River: history and environmental consequences. U.S. Geological Survey Scientific Investigations Report. 2011-5122.

Birstein, VJ. 1993. Sturgeons and Paddlefishes: Threatened Fishes in Need of Conservation. Conservation Biology. 7(4): 773-787

Birstein, VJ, R Hanner, and R DeSalle. 1997. Phylogeny of the Acipenseriformes: Cytogenetic and molecular approaches. Environmental Biology of Fishes. 48(1-4): 127-156.

Blacklidge, $\mathrm{KH}$ and CA Bidwell. 1993. Three ploidy levels indicated by genome quantification in Acipenseriformes of North America. Journal of Heredity. 84(6): 427-430. 
Boase, JC, JS Diana, MV Thomas, JA Chiotti. 2011. Movements and distribution of adult Lake Sturgeon from their spawning site in the St. Clair River, Michigan. Journal of Applied Ichthyology. 27(2): 58-65.

Bossdorf, O, CL Richards, and M Pigliucci. 2008. Epigenetics for ecologists. Ecology Letters. 11(2): 106-115.

Boulet, M, E Normandeau, B Bougas, C Audet, L Bernatchez. 2012. Comparative transcriptomics of anadromous and resident brook charr Salvelinus fontinalis before their first salt water transition. Current Zoology. 58(1): 158-170.

Bernatchez, L, CC Wilson. 1998. Comparative phylogeography of Nearctic and Palearctic fishes. Molecular Ecology. 7: 431-452.

Chapman, BB, C Bronmark, J Nilsson, and L Hansson. 2011. The ecology and evolution of partial migration. Oikos. 120: 1764-1775.

Chapman, BB, C Skov, K Hulthen, J Brodersen, PA Nilsson, LA Hansson, and C Bronmark. 2012. Partial migration in fishes: definitions, methodologies and taxonomic distribution. Journal of Fish Biology. 81: 479-499.

Chiasson, W.B., D.L.G. Noakes, F.W.H. Beamish. 1997. Habitat, benthic prey, and distribution of juvenile lake sturgeon (Acipenser fulvescens) in northern Ontario Rivers. Canadian Journal Fisheries and Aquatic Sciences. 54: 2866-2871.

Costa, C, E Tibaldi, L Pasqualetto, and A Loy. 2006. Morphometric comparison of the cephalic region of cultured Acipenser baerii (Brandt, 1869), Acipenser naccarii (Bonaparte, 1836) and their hybrid. Journal of Applied Ichthyology. 22: 8-14.

Dadswell, MJ. 1979. Biology and population characteristics of the shortnose sturgeon Acipenser brevirostrum osteichthyes acipenseridae in the St. John River Estuary New Brunswick, Canada. Canadian Journal of Zoology. 57(11): 2186-2210.

DeHaan, P.W., S.V. Libants, R.F. Elliott, and K.T. Scribner. 2008. Genetic Population Structure of Remnant Lake Sturgeon Populations in the Upper Great Lakes Basin. Transactions of the American Fisheries Society. 135:1478-1492.

Dingle, H. 1996. Migration: The biology of life on the move. Oxford Univ. Press.

DiBattista, JD. 2008. Patterns of genetic variation in anthropogenically impacted populations. Conservation Genetics. 9: 141-156.

DiVincenti, L, J Wyatt, H Priest, D Dittman, R Klindt, D Gordon, A Preston, T Smith, C Bowman. 2013. Reference intervals for select hematologic and plasms biochemical analytes of wild Lake Sturgeon (Acipenser fulvescens) from the St. Lawrence River in New York. Veterinary Clinical Pathology. 42(1): 19-26. 
Ferguson, M Moira, and G Duckworth. 1997. The status and distribution of lake sturgeon, Acipenser fulvescens, in the Canadian provinces of Manitoba, Ontario and Quebec: a genetic perspective. Environmental Biology of Fishes 48: 299-309.

Foll, M. and O Gaggiotti. 2008. A genome-scan method to identify selected loci appropriate for both dominant and codominant markers: A Bayesian perspective. Genetics. 180: 977-993.

Fortin, R, P Dumont, and S Guénette. 1996. Determinants of growth and body condition of lake sturgeon (Acipenser fulvescens). Canadian Journal of Fisheries and Aquatic Science. 53: 11501156

Guenette, S, E Rasser, and R Fortin. 1992. Morphological differentiation of lake sturgeon (Acipenser fulvescens) from the St. Lawrence River and Lac des Deux Montagnes (Quebec, Canada). Canadaan Journal of Fisheries and Aquatic Sciences. 49(9): 1959-1965.

Hale, MC, CR McCormick, JR Jackson, and JA DeWoody. 2009. Next-generation pyrosequencing of gonad transcriptomes in the polyploid lake sturgeon (Acipenser fulvescens): the relative merits of normalization and rarefaction in gene discovery. BMC Genomics. 10:203.

Harkness, WJK and JR Dymond. 1961. The lake sturgeon: the history of its fishery and problems of conservation. Ontario Department of Lands and Forests. Toronto, Ontario.

Hay-Chmielewski, EM, and GE Whelan. 1997. Lake sturgeon rehabilitation strategy. Michigan Department of Natural Resources Fisheries Division, Special Report 18, Ann Arbor.

Herrera, CM and P Bazaga. 2011. Untangling individual variation in natural populations: ecological, genetic and epigenetic correlates of long-term inequality in herbivory. Molecular Ecology. 20(8): 1675-1688.

Jablonka, E. 2012. Epigenetic inheritance and plasticity: the responsive germline. Progress in Biophysics and Molecular Biology. 111: 99-107.

Jeon, TJ. 2008. DNA adenine methylation of sams1 gene in symbiont bearing Amoeba proteus. The Journal of Microbiology. 46: 564-570.

Klassen, CN, and SJ Peake. 2008. Effect of diet switch timing and food source on survival and growth of lake sturgeon. Journal of Applied Ichthyology. 24: 527-533.

Kovach, RP, JE Joyce, JD Echave, MS Lindberg, and DA Tallmon. 2013. Earlier migration timing, decreasing phenotypic variation, and biocomplexity in multiple salmonid species. PLoS ONE. 8. e53807.

Krieger, J, AK Hett, PA Fuerst, E Artyukhin, and A Ludwig. 2007. The molecular phylogeny of the order Acipenseriformes revisited. Journal of Applied Ichthyology. 24(1): 36-45.

LaHaye, M, A Branchaud, and M Gendron. 1992. Reproduction, early life-history, and characteristics of the spawning grounds of lake sturgeon (Acipenser fulvescens) in Des-Prairies 
and Lassomption Rivers, near Montreal, Quebec. Canadian Journal of Zoology. 70(9): 16811689.

Latta, RG. 2008. Conservation genetics as applied evolution: from genetic pattern to evolutionary process. Evolutionary Applications. 1: 84-89.

Layeghifard, M, PR Peres-Neto, and V Makarenkov. 2012. Using directed phylogenetic networks to retrace species dispersal history. Molecular Phylogenetics and Evolution. 64: 190197.

Liedvogel, M, S Akesson, and S Bensch. 2011. The genetics of migration on the move. Trends in Ecology and Evolution. 26(11): 561-569.

Lyons, J, and JJ Kempinger. 1992. Movements of adult lake sturgeon in the Lake Winnebago system. Wisconsin Department of Natural Resources. No. RS-156-92.

Mailhot, Y, P Dumont and N Vachon. 2011. Management of the Lake Sturgeon Acipenser fulvescens population in the lower St. Lawrence River (Que'bec, Canada) from the 1910s to the present. Journal of Applied Ichthyology. 27: 405-410.

Mandrak, Nicholas E and E.J. Crossman. 1992. Postglacial dispersal of freshwater fishes in Ontario. Canadian Journal of Zoology. 70: 2247-2259.

Massicotte R, E Whitelaw, B Angers. 2011. DNA methylation: a source of random variation in natural populations. Epigenetics. 6: 421-7.

McDermid, JL, KM Wozney, SL Kjartanson, CC Wilson. 2011. Quantifying historical, contemporary, and anthropogenic influences on the genetic structure and diversity of lake sturgeon (Acipenser fulvescens) populations in northern Ontario. Journal of Applied Ichthyology. 27: 12-23.

McDermid, JL, S Nienhuis, M Al-Shamlih, TJ Haxton, and CC Wilson. 2014. Evaluating the genetic consequences of river fragmentation in lake sturgeon (Acipenser fulvescens Rafinesque, 1817) populations. Journal of Applied Ichthyology. 30: 1514-1523.

North, JA, RA Farr, and P Vescei. 2002. A comparison of meristic and morphometric characters of green sturgeon Acipencermedirostris. Journal of Applied Ichthyology. 18: 234-239.

Ogden, R, K Gharbi, N Mugue, J Martinsohn, H Senn, JW Davey, M Pourkazemi, R McEwing, C Eland, M Vidotto, A Sergeev, and L Congiu. 2013. Sturgeon conservation genomics: SNP discovery and validation using RAD sequencing. Molecular Ecology. 22: 3112-3123.

Ogonowski, MS and CJ Conway. 2009. Migratory decisions in birds: extent of genetic versus environmental control. Oecologia. 161:199-207. 
O’Malley, KG, DP Jacobson, R Kurth, AJ Dill, and MA Banks. 2013. Adaptive genetic markers discriminate migratory runs of Chinook salmon (Oncorhynchus tshawytscha) amid continued gene flow. Evolutionary Applications. 6(8): 1184-1194.

Peterson DL, P Vecsei, and CA Jennings. 2007. Ecology and biology of the lake sturgeon: a synthesis of current knowledge of a threatened North American Acipenseridae. Reviews in Fish Biology and Fisheries. 17: 59-76.

Pollack, MS, M Carr, NM Kreitals, ID Phillips. Review of a species in peril: what we do not know about lake sturgeon may kill them. Environmental Reviews. 23(1): 30-43.

Pulido, F. 2011. Evolutionary genetics of partial migration - the threshold model of migration revisited. Oikos. 120: 1776-1783.

Rosenberg, DM, P McCully, and CM Pringle. 2000. Global-scale environmental effects of hydrological alterations: Introduction. Bioscience. 50: 746-751.

Ruban, GI, and LI Sokolov. 1986. Morphological variability of Siberian sturgeon, Acipenser baerii, in the Lena River in relation with its culture in warm water. Journal of Ichthyology. 26: 88-94.

Rusak, JA and T Mosindy. (1997). Seasonal movements of lake sturgeon in Lake of the Woods and the Rainy River, Ontario. Canadian Journal of Zoology. 74: 383-395.

Schrey, AW, CAC Coon, MT Grispo, M Awad, T Imboma, ED McCoy, HR Mushinsky, CL Richards, and LB Martin. 2012. Epigenetic Variation May Compensate for Decreased Genetic Variation with Introductions: A Case Study Using House Sparrows (Passer domesticus) on Two Continents. Genetics Research International. Article ID 979751: 1-7.

Scott, WV, and EJ Crossman. 1973. Freshwater fishes of Canada. Fisheries Research Board of Canada.

Shively, JD and N Kmiecik. 1989. Inland fisheries enhancement activities within the ceded territory of Wisconsin during 1988. Admin Rep No. 89-1. Great Lakes Indian Fish and Wildlife Commission, Odanah Wisch.

Stockwell, CA, AP Hendry, and MT Kinnison. 2003. Contemporary evolution meets conservation biology. Trends in Ecology and Evolution. 18: 94-101.

Strayer, D. L.; Dudgeon, D., 2010: Freshwater biodiversity conserva- tion: recent progress and future challenges. Journal of North American Benthological Society. 29: 344-358.

Thuemler, TF. 1997. Lake sturgeon management in the Menominee River, a WisconsinMichigan boundary water. Environmental Biology of Fishes. 48(1): 311-318. 
Threader, RW and CS Brousseau. 1986. Biology and management of lake sturgeon (Acipenser fulvescens) in the Moose River Ontario Canada. North American Journal of Fisheries Management. 6(3): 383-390.

Varriale, A and G Bernardi. 2006. DNA methylation and body temperature in fishes. Gene. 385: 111-121.

Vasil'eva, ED. 2009. Morphological and morphometric characters in sturgeon taxonomy and phylogeny. In: Carmona, R, A Domezain, M Garc' 1a-Gallego, JA Hernando, F Rodriguez, M Ruiz-Rejon (Eds): Biology, Conservation and Sustainable Development of Sturgeons, (1): 5161. Springer, Media, BV, Berlin, Heidelberg.

Veshchev, PV and AS Novikova. 1983. Reproduction of stellate sturgeon Acidpenser stellatus, Acipenseridae under conditions of altered flow of the Volga River, Russian SFSR USSR. Voprosy Ikhtiologii. 23(5): 766-773.

Walsh, MG, MB Bain, JRT Squiers, JR Waldman, and I Wirgin. 2001. Morphological and genetic variation among short- nose sturgeon Acipenser brevirostrum from adjacent and distant rivers. Estuaries 24: 41-48.

Weaver, ICG, N Cervoni, FA Champagne, AC D'Alessio, S Sharma, JR Seckl, S Dymov, M Szyf, and MJ Meaney. 2004. Epigenetic programming by maternal behavior. Nature Neuroscience. 7(8): 847-854.

Welsh, AB, T Hill, H Quinlan, C Robinson, and B May. 2008. Genetic assessment of lake sturgeon population structure in the Laurentian Great Lakes. North American Journal of Fisheries Management. 28: 572-591.

Welsh, AB, RF Elliott, KT Scribner, HR Quinlan, EA Baker, BT Eggold, JM Holtgren, CC Krueger, B May. Genetic guidelines for the stocking of lake sturgeon (Acipenser fulvescens) in the Great Lakes basin. Great Lakes Fisheries Commission. Miscellaneous Publication. 2010-01.

Welsh, AB, and DT McLeod. 2010. Detection of natural barriers to movement of lake sturgeon (Acipenser fulvescens) within the Namakan River, Ontario. Canadian Journal of Zoology. 88: 390-397.

Wills, PS; RJ Sheehan, R Heidinger, BL Sloss, R Clevenstine. 2002. Differentiation of pallid sturgeon and shovelnose sturgeon using an index based on meristics and morphometrics. American Fisheries Society Symposium. 28: 249-258.

Welsh, A. 2004. Factors influencing the effectiveness of local versus national protection of migratory species: a case study of lake sturgeon in the Great Lakes, North America. Environmental Science and Policy. 7: 315-328.

Welsh, A and B May. 2006. Development and standardization of disomic microsatellite markers for lake sturgeon genetic studies. Journal of Applied Ichthyology. 22: 337-344. 
Wozney, K.M., T.J. Haxton, S. Kjartanson, and C.C. Wilson. 2011. Genetic assessment of lake sturgeon (Acipenser fulvscens) population structure in the Ottawa River. Environmental Biology of Fishes. 90: 183-195. 




\section{Lake Huron}

St. Clair River



\section{FIGURE 1.1}

The St. Clair-Detroit River System (SCDRS). The SCDRS includes Lake Huron, the St. Clair and Detroit rivers, Lake St. Clair, and Lake Erie. 


\section{Chapter 2: Genetic Structure of Lake Sturgeon in the St. Clair-Detroit River System}

\section{Introduction}

Globally, sturgeon are among some of the most threatened species due to over-harvest, habitat degradation, and pollution (Lenhardt et al., 2006). Lake sturgeon (Acipenser fulvescens), found in the Hudson Bay, Great Lakes and Mississippi River, have experienced population declines, with some populations reduced to $1 \%$ of their historic numbers (Harkness and Dymond, 1961; Auer, 1996). Since lake sturgeon is an economically and culturally valuable species, fishing restrictions have been implemented, but populations have not been restored in most of the lake sturgeon range.

Genetic methods can provide insight into ancestry, evolutionary potential, and demography, aiding in management by delineation of populations and management units (DiBattista, 2008; Latta, 2008; Stockwell et al., 2003,). The population structure of fish in the Great Lakes may be strongly influenced by the phylogeographic history of the area, which includes multiple episodes of displacement followed by recolonization (Bernatchez and Wilson, 1998). Great Lakes-wide population structure analyses using neutral markers have been performed, showing that lake sturgeon are genetically diverse throughout their range and most spawning populations are genetically distinct (DeHaan et al., 2008; Welsh et al., 2008). Based on analysis of 12 microsatellite loci, the Detroit River and the St. Clair River, the rivers that connect Lake Huron to Lake Erie, appear to contain only one spawning population (Welsh et al., 2008), which is to be expected in a system with no dams or impediments to movement.

In contrast to genetic data, movement data of lake sturgeon in the St. Clair-Detroit River System (SCDRS) suggest that there may be multiple populations (Hondorp, personal 
communication; Thomas and Haas 2002). Lake sturgeon are known to exhibit site fidelity (Auer, 1999; Barth et al., 2011; Gunderman and Elliott, 2004), which can result in high degrees of population structure. Within systems where there are no barriers to gene flow, population structure may arise from differences in timing of migration (O’Malley et al., 2013). It is reasonable to hypothesize that there are multiple populations within the SCDRS that are associated with the five known spawning locations in the St. Clair and Detroit Rivers. Although genetic analyses have been performed on the SCDRS, incorporating more samples $(n=97)$ and more detailed sampling locations will provide a more robust analysis to determine whether there is gene flow across the system. The main goal of this study was to use the sampling location, which corresponds to the spawning sites in the SCDRS in combination with microsatellite genotyping to identify fine-scale population structure.

The SCDRS may have contained as many as 15 spawning sites at one time (Goodyear et al., 1982), but spawning habitat has been removed or degraded due to dredging for the shipping channel (Manny, 2003; Read and Manny, 2006). The SCDRS now consists of a few historic spawning sites and recently created artificial reefs built to support increased spawning of native fish (Read and Manny, 2006; Roseman et al., 2011; Figure 2.1). The St. Clair River currently has at least two known active lake sturgeon spawning sites. In the upper St. Clair River there is a site beneath the Blue Water Bridge that is greater than 67 hectares and consists of large cobble and igneous gravel (Manny and Kennedy, 2002; Nichols et al., 2003). The North Channel spawning site near the lower portion of the St. Clair River is over 100 years old and is an accidentally created artificial reef consisting of a coal clinker bed (Manny and Kennedy, 2002; Nichols et al., 2003). There is also an artificial reef that was built in the Middle Channel in 2012 and spawning of lake sturgeon has been reported (Marranca et al., 2015). There are additional spawning sites in 
the Detroit River. One site consists of glacial gravel and coal clinkers and is located near Zug Island (Caswell et al., 2004; Manny and Kennedy, 2002). An artificial reef was built near Fighting Island in 2008 (Roseman et al., 2011). Lastly, there is an artificial reef that was built near Belle Isle in 2004. This site has not been confirmed as an active lake sturgeon spawning site, although other species of native fish have used this site for spawning (Manny et al., 2007; Read and Manny, 2006).

Determining whether this is a panmictic population, or if there is genetic structure, could alter whether the population is managed as one large population, or multiple smaller ones. Smaller populations are at a greater risk of extinction (Gilpin and Soule, 1986) due to the potential for inbreeding and subsequent inbreeding depression, as well as the deterioration of genetic diversity and evolutionary potential (Allendorf and Leary, 1986; Amos and Balmford 2001). Gene flow from effective migrants between populations is a critical mechanism for increasing diversity of populations. Fragmented habitats can interfere with gene flow, especially in impacted systems such as the SCDRS. Management strategies for stocking, reintroductions, and habitat alterations may be refined by including genetic information.

\section{Methods}

Study Site

The SCDRS, a part of the Great Lakes, consists of two major lakes and a river corridor connecting them (Figure 2.1). There is little fluctuation in flow and there are stable changes in temperature throughout the year. Lake Huron is approximately 230 meters deep and temperatures can vary from about $0^{\circ} \mathrm{C}$ to over $25^{\circ} \mathrm{C}$. Lake Erie is shallow, and is the warmest of the Great Lakes (Letcher et al., 2015). The corridor connecting the two lakes consists of the St. 
Clair River, Lake St. Clair, and the Detroit River. The St. Clair River, which is 64 kilometers long, connects Lake Huron and Lake St. Clair (Boase et al., 2011). Depths in the river range from 8-24 meters, and velocities vary (Edsall et al., 1988), with the highest velocity occurring around the International Blue Water Bridge. Lake St. Clair is, on average, about 3 meters deep and has a short retention time of water, functioning similarly to a shallow river (Schwab and Clites, 1986; Thomas and Haas, 2002). The Detroit River, which is 51 kilometers long, connects Lake St. Clair with Lake Erie (Caswell et al., 2004). The corridor (consisting of Lake St. Clair, and the St. Clair and Detroit Rivers) form an important shipping channel connecting the upper and lower Great Lakes. Sediment removal, as much as 46 million $\mathrm{m}^{3}$ from the Detroit River, and shipping channel construction has contributed to the degradation of the fish habitat within the SCDRS (Bennion and Manny, 2011); however, there are no dams within the SCDRS.

\section{Sampling}

Lake sturgeon were captured during spawning season (May-June between 2011-2015) as part of population surveys conducted by the Michigan Department of Natural Resources in the lower St. Clair and Detroit Rivers, and by the U.S. Fish and Wildlife Service in the upper St. Clair River. Sturgeon collections were supplemented with fish captured by commercial fishermen in southeast Lake Huron approximately $15 \mathrm{~km}$ NNE of the Blue Water Bridge. Most lake sturgeon were captured using baited set lines deployed from a research vessel in the afternoon and retrieved the following morning (Thomas and Haas, 2002). Sturgeon supplied by commercial fisherman were collected as by-catch in trapnets. 


\section{Laboratory Techniques}

DNA was extracted from fin clips ( $\mathrm{n}=121)$ using the Gentra Puregene Tissue Kit (CQiagen, Germantown, MD, USA) according to manufacturer's protocol and extracts were quantified on the Nanodrop (CThermoscientific, Wilmington, DE, USA). Extracted DNA was analyzed at 12 microsatellite loci: AfuG9, AfuG56, AfuG63, AfuG74, AfuG112, AfuG160, AfuG195, AfuG204, Afu68, Afu68b, Spl120, Aox27 (Welsh and May, 2006). PCR amplification was done using the Qiagen Multiplex PCR Kit ${ }^{\circledR}$ (Germantown, MD, USA). Four primer mixes were prepared. Primer mix 1 (AfuG 56, Spl120 and AfuG 195), primer mix 2 (AfuG204, AfuG74, and AfuG9), and primer mix 3 (AfuG160, Aox27 and AfuG112) contained $2 \mu \mathrm{M}$ final concentration of each primer. Primer mix 4 included Afu68 and AfuG68b primers (final concentration of $1 \mu \mathrm{M}$ ) and AfuG63 primers (final concentration of $2 \mu \mathrm{M}$ ). The Mulitplex PCR Master Mix (final concentration of $1 \mathrm{X}$ ) was used in a total reaction volume of $10 \mu 1$, with $20 \mathrm{ng}$ of extracted DNA. The PCR conditions for primer mix 1 were $95^{\circ} \mathrm{C}$ for 15 minutes; 15 cycles of $94^{\circ} \mathrm{C}$ for 30 seconds, $60^{\circ} \mathrm{C}$ for 90 seconds with a $0.5^{\circ}$ decrease with each cycle, $72^{\circ} \mathrm{C}$ for 60 seconds; 15 cycles of $94^{\circ} \mathrm{C}$ for 30 seconds, $52^{\circ} \mathrm{C}$ for 90 seconds, $72^{\circ} \mathrm{C}$ for 60 seconds; $60^{\circ} \mathrm{C}$ for 30 minutes. The PCR conditions for primer mixes $2-4$ were $95^{\circ} \mathrm{C}$ for 15 minutes; 35 cycles of $94^{\circ} \mathrm{C}$ for 30 seconds, $57^{\circ} \mathrm{C}$ for 90 seconds, $72^{\circ} \mathrm{C}$ for 60 seconds; $60^{\circ} \mathrm{C}$ for 30 minutes. PCR products were then visualized on a Beckman Coulter GeXP Genetic Analysis System.

\section{Population Clustering and Genetic Differentiation}

After genotyping the fish at 12 microsatellites, the most likely number of populations in the SCDRS was determined. A Bayesian approach for population clustering was performed using the software STRUCTURE (Pritchard et al., 2000), which estimates the likelihood of population clusters based on Hardy-Weinberg equilibrium (HWE) and linkage disequilibrium. A 
burn-in length of 100,000 and 100,000 MCMC steps were used for 10 iterations under the admixture model. It was assumed that the allele frequencies were correlated. Since samples were taken during spawning season, the sampling location was used as prior knowledge, and suggests the likely spawning site. An iterative approach was used until a K of one was achieved. HardyWeinberg equilibrium (HWE) was tested for each locus and population using the software GENEPOP 4.2 (Raymond and Rousset, 1995), which utilizes an exact probability test estimated by Markov chain algorithms. The following parameters were used: 10,000 burn-in, 100 batches, 1,000 iterations, and $\alpha<0.05$. Significance of the HWE tests was determined after performing a sequential Bonferroni correction (Rice, 1989). Linkage disequilibrium was tested for pairs of loci using probability tests, via GENEPOP 4.2 (Raymond and Rousset, 1995). A burn-in length of 10,000 was used for 100 batches and 1,000 iterations.

A Discriminant Analysis of Principal Components (DAPC) was performed using the adegenet package in R (cran mirror: USA PA1) to identify variation in genotypes between population locations (Jombart, 2008). The DAPC uses Principal Component Analysis prior to the Discriminant Analysis (Jombart et al., 2010). As there were only three locations (upper St. Clair, lower St. Clair, and Detroit Rivers) used in the analysis, two DAPC axes were retained. Twentyfive PCs were retained, as 25 had the lowest root mean squared error (10\%) and had a decreased likelihood of overfitting the data.

The genotypes of fish were used to determine genetic differentiation between the three locations. The $F_{\mathrm{ST}}$ value between the three groups was calculated using the program FSTAT 2.9.3.2 (Goudet, 1995), which implements the method outlined in Weir and Cockerham (1984), to determine if the three groups were genetically distinct $(\mathrm{p} \leq 0.05) . F_{\mathrm{ST}}$ values range from 0 to 1 and larger numbers correspond to increased genetic differentiation. 


\section{Assignment of Potential Migrants}

To determine the origin of potential migrants in the individuals sampled from the Upper St. Clair River, a Bayesian-based method was applied through the program GeneClass2 (Piry et al., 2004). Detection of first generation migrants was performed using the criteria outlined in Rannala and Mountain (1997). The number of Monte Carlo-simulated individuals was set to 1000. An individual was considered a migrant based on the ratio of $\mathrm{L}_{\text {home }} / \mathrm{L}_{\max }$, with a probability threshold of 0.05 . $\mathrm{L}_{\text {home }}$ is the likelihood that the sample is from the location where it was sampled and Lmax is the likelihood among all samples. Fish from the Upper St. Clair River were also assigned to a putative population of origin using GeneClass2 (Piry et al., 2004) with the same criteria as listed above for detection of first generation migrants. The probability computation was enabled, using Monte Carlo resampling, as described in Paetkau et al. (2004). Fish were assigned using baseline data that had been previously genotyped (Welsh et al., 2008). Genotyping of Lake Huron potential populations of origin (Mississaugi, $n=52$; Nippissing, $n=75$; Spanish, $\mathrm{n}=47$; and St. Clair, $\mathrm{n}=50$ rivers) was performed as described above.

A second Bayesian method, implemented through the software program STRUCTURE (Pritchard et al., 2000), was employed to identify potential migrants in the Upper St. Clair River population. The number of population clusters was estimated as described above to determine the most likely value for $K$. The number of potential first generation migrants was then estimated using the following criteria: number of generations back was set to 1 , the migration prior was set to 0.05 , correlated allele frequencies were assumed, the sampling location was used as a prior, and the admixture model was used. 


\section{Results}

\section{Population Clustering and Genetic Differentiation}

Bayesian analysis, implemented by the program STRUCTURE, revealed that within the SCDRS the most likely number of populations is two $(K=2)$ (Figure 2.2a,b). The Detroit and the lower St. Clair Rivers are one population, established through the iterative approach used (Figure 2.2). However, there is some structure within the upper St. Clair cluster. The STRUCTURE plots show that this is not a clear division of two populations (Figure 2.2c,d). It is possible that this population may be receiving migrants from an outside population of lake sturgeon that have migrated into the St. Clair River by way of Lake Huron.

The $F_{S T}$ values calculated for the three locations support the STRUCTURE results that migrants may be providing gene flow to the upper St. Clair River spawning site (Table 2.1). The upper St. Clair River is significantly differentiated from the lower St. Clair, with an $F_{S T}$ value of 0.0135 (Table 2.1). $F_{S T}$ values range from 0 to 1 , and this value is considered to be a slight genetic differentiation. However, none of the other $F_{S T}$ values are significant, suggesting that neither the upper nor lower St. Clair River is genetically differentiated from the Detroit River.

Results from the DAPC on the genotypes of fish classified by location also show some evidence for multiple populations (Figure 2.3). The clusters for all three locations showed some overlap within the first two axes of the DAPC space, but there are three apparent clusters.

No loci showed evidence of linkage disequilibrium, and after a sequential Bonferroni correction, no loci were deemed to be out of HWE.

\section{Assignment of Potential Migrants}


Potential migrants were identified using the Bayesian method implemented in GeneClass2. Five potential first generation migrants were identified (Table 2.2). Of these five individuals, two were assigned to the St. Clair River population, with varying success (Table 2.2). Three migrants were assigned to the Nippissing River, one with a fairly high probability, suggesting that the Nippissing may be one source of the migrant gene flow. The Bayesian method implemented through STRUCTURE only identified one migrant, which was also identified using GeneClass2.

\section{Discussion}

The results of this study indicate that there may be some fine scale genetic structure to the population of lake sturgeon in the SCDRS. This contradicts the previous genetic evidence indicating that the SCDRS was one population (Welsh et al., 2008). However, levels of genetic differentiation are low, with only the upper St. Clair River statistically differentiated from the other locations in the SCDRS. The low level of genetic structure in the SCDRS suggests that there is still connectivity across the system, which may be important for maintaining genetic diversity within this large population of lake sturgeon. Evidence of some population structure in the SCDRS may be indicative that there is less site fidelity in this system than has been documented in other systems (Auer, 1999; Barth et al., 2011; Forsythe et al., 2012; Gunderman and Elliott, 2004; Lyons and Kempinger1992). Low site fidelity may be due to the lack of impediments to movements in the SCDRS, facilitating gene flow.

The potential migrants identified in this study may be from outside of the baseline populations used for assignment. Through Lake Huron, the SCDRS is connected to the majority of the rest of the Great Lakes. Fish from the SCDRS have been known to move as far as Green Bay Michigan (James Boase, personal communication), and it is plausible that fish from 
populations outside of Lake Huron have migrants contributing to the genetic structure of the SCDRS. Increasing the number of baseline populations that span a wider geographic area may improve assignment.

There may be additional genetic structure that was not visible using the methods outlined in this study. The addition of genome wide markers, such as single nucleotide polymorphisms may elucidate genetic structure. Additionally, performing an analysis including both neutral and adaptive markers might reveal fine scale population structure that has not been uncovered using neutral markers alone. Spawning of lake sturgeon occurs in the spring and is dependent upon environmental cues, such as photoperiod (Bizzotto et al., 2009; Quinn \& Adams, 1996) and water temperature (Forsythe et al., 2012), and is predictable from year to year (Forsythe, 2010; Forsythe et al., 2012). Traits related to migration may be appropriate adaptive markers for lake sturgeon populations. Utilizing adaptive markers may provide further insight into population structure. Adaptive divergence has been found in rainbow smelt (Osmerus mordax; SaintLaurent et al., 2003), the Pacific leaping blenny (Alticus amoldorum, Morgans et al., 2014) and rainbow trout (Oncorhynchus mykiss; Van Doornik et al., 2013) despite gene flow. Adaptive markers may also be useful in better understanding the identified population structure that was not clearly explained through the assignment of potential migrants based on neutral markers alone.

Knowing the population structure of the lake sturgeon in the SCDRS may be important for developing a sustainable management plan. Currently, the SCDRS is managed as one population. This is likely to be continued as the SCDRS is barrier-free and it is clear that there is gene flow across the system. The level of population structure in the upper St. Clair River may be due to migrants that are using the Blue Water Bridge spawning site, generating a low level of 
gene flow from a second population. This site is a large and historic spawning site for lake sturgeon and it is possible that it could support additional fish moving into the system. The Nippissing River population may be contributing gene flow to the SCDRS, but identifying additional source populations of putative migrants would be useful in understanding the potential for continued gene flow and the possibility of adverse affects, such as outbreeding depression. 


\section{References}

Allendorf, FW and RF Leary. 1986. Heterozygosity and fitness in natural populations of animals. Conservation Biology: The Science of Scarcity and Diversity. Soule, ME (ed). pp. 57-76.

Amos, W, and A Balmford. 2001. When does conservation genetics matter? Heredity. 87(3): 257-265. doi:10.1046/j.1365-2540. 2001.00940.x. PMID:11737272.

Auer, N. 1996. Importance of habitat and migration to sturgeons with emphasis on lake sturgeon. Canadian Journal of Fisheries and Aquatic Science. 53(1): 152-160.

Auer, NA. 1999. Population characteristics and movements of lake sturgeon in the Sturgeon River and Lake Superior. Journal of Great Lakes Research. 25: 282-293.

Barth, CC, WG Anderson, LM Henderson, and SJ Peake. 2011. Home range size and seasonal movement of juvenile lake sturgeon in a large river in the Hudson Bay drainage basin. Transactions of American Fisheries Society. 140: 1629-1641. doi:10.1080/ 00028487.2011.641881.

Bennion, DH, Manny, BA. 2011. Construction of shipping channels in the Detroit River: history and environmental consequences. U.S. Geological Survey Scientific Investigations Report. 2011-5122.

Bernatchez, L and CC Wilson. 1998. Comparative phylogeography of Nearctic and Palearctic fishes. Molecular Ecology. 7: 431-452.

Bizzotto, PM, AL Godinho, V Vono, B Kynard, and HP Godinho. 2009. Influence of seasonal, diel, lunar, and other environmental factors on upstream fish passage in the Igarapava Fish Ladder, Brazil. Ecology of Freshwater Fish. 18: 461-472.

Boase, JC, JS Diana, MV Thomas, JA Chiotti. 2011. Movements and distribution of adult Lake Sturgeon from their spawning site in the St. Clair River, Michigan. Journal of Applied Ichthyology. 27(2): 58-65.

Caswell, NM, DL Peterson, BA Manny, GW Kennedy. 2004. Spawning by lake sturgeon (Acipenser fulvescens) in the Detroit River. Journal of Applied Ichthyology. 20: 1-6.

DeHaan, PW, SV Libants, RF Elliott, and KT Scribner. 2008. Genetic Population Structure of Remnant Lake Sturgeon Populations in the Upper Great Lakes Basin. Transactions of the American Fisheries Society. 135: 1478-1492.

DiBattista, JD. 2008. Patterns of genetic variation in anthropogenically impacted populations. Conservation Genetics. 9: 141-156.

Edsall, TA, BA Manny, CN Raphael. 1988. The St. Clair River and Lake St. Clair, Michigan: an ecological profile. US Fish and Wildlife Service, Biological Report. 85(7.3). Slidell, LA. 
Forsythe, PS. 2010. External correlates of migratory and spawning activity and egg deposition and mortality in lake sturgeon Acipenser fulvescens. PhD Thesis, Department of Zoology, Michigan State University. East Lansing, MI, USA.

Forsythe PS, KT Scribner, JA Crossman, A Ragavendran, EA Baker, C Davis, KK Smith. 2012. Environmental and lunar cues are predictive of the timing of river entry and spawning-site arrival in lake sturgeon Acipenser fulvescens. Journal of Fish Biology. 81:35-53.

Gilpin, ME and ME Soulé. 1986. Minimum viable populations: processes of species extinction. In: Conservation Biology, The Science of Scarcity and Diversity. Soulé, ME (ed.), Sinauer Associates Publishers, Sunderland. pp. 19-34.

Goodyear, CS, TA Edsall, DM Ormsby Dempsey, GD Moss, PE Polanski. 1982. Atlas of spawning and nursery areas of Great Lakes fishes: Detroit River. 8. US Fish and Wildlife Service, Washington, DC, FWS/OBS 82/52.

Goudet, J. 1995. FSTAT (Version 1.2): A computer program to calculate F-statistics. Journal of Heredity. 86:485-486.

Gunderman, BJ, and RF Elliott. 2004. Assessment of remnant lake sturgeon populations in the Green Bay Basin, 2000-2003. Report to the Great Lakes Fishery Trust, Project 2001.113, Lansing, Michigan.

Harkness, WJK and JR Dymond. 1961. The lake sturgeon: the history of its fishery and problems of conservation. Ontario Department of Lands and Forests. Toronto, Ontario.

Jombart,T. 2008. Adegenet: an R package for the multivariate analysis of genetic markers. Bioinformatics 24: 1403-1405. doi:10.1093/bioinformatics/btn129

Jombart, T, S Devillard, and F Balloux. 2010. Discriminant analysis of principal components: a new method for the analysis of genetically structured populations. BMC Genetics 11:94. doi:10.1186/1471-2156-11-94.

Latta, RG. 2008. Conservation genetics as applied evolution: from genetic pattern to evolutionary process. Evolutionary Applications. 1: 84-89.

Lenhardt, M, I Jaric, A Kalauzi, G Cvijanovic. 2006. Assessment of extinction risk and reasons for decline in sturgeon. Biodiversity Conservation. 15: 1967-2002.

Letcher, RJ, Z Lu, SR de Solla, CD Sandau, KJ Fernie. 2015. Snapping Turtles (Chelydra serpentina) from Canadian Areas of Concern across the southern Laurentian Great Lakes: Chlorinated and brominated hydrocarbon contaminants and metabolites in relation to circulating concentrations of thyroxine and vitamin A. Environmental Research. 143: 266-278.

Lyons, J, and JJ Kempinger. 1992. Movements of adult lake sturgeon in the Lake Winnebago system. Wisconsin Department of Natural Resources Research. Publication No. RS-156-92. 
Manny, BA, and GW Kennedy. 2002: Known lake sturgeon (Acipenser fulvescens) spawning habitat in the channel between lakes Huron and Erie in the Laurentian Great Lakes. Journal of Applied Ichthyology. 18: 486-490.

Manny, BA, GW Kennedy, JD Allen, and JRP French. 2007. First evidence of egg deposition by walleye (Sander vitreus) in the Detroit River. Journal of Great Lakes Research 33: 512-516.

Marranca, JM, AB Welsh, E Roseman. 2015. Genetic effects of habitat restoration in the Laurentian Great Lakes: an assessment of lake sturgeon origin and genetic diversity. Restoration Ecology. 23(4): 455-464.

Morgans, CL, GM Cooke, and TJ Ord. 2014. How populations differentiate despite gene flow: sexual and natural selection drive phenotypic divergence within a land fish, the Pacific leaping blenny. BMC Evolutionary Biology. 14:97.

Nichols, SJ, G Kennedy, E Crawford, J Allen, J French III, G Black, M Blowin, J Hickey, S Chernyak, R Haas, M Thomas. 2003: Assessment of lake sturgeon (Acipenser fulvescens) spawning efforts in the lower St. Clair River, Michigan. Journal of Great Lakes Research. 29: 383-391.

O’Malley, KG, DP Jacobson, R Kurth, AJ Dill, and MA Banks. 2013. Adaptive genetic markers discriminate migratory runs of Chinook salmon (Oncorhynchus tshawytscha) amid continued gene flow. Evolutionary Applications. 1752-4571.

Paetkau, D, R Slade, M Burden, and A Estoup. 2004. Direct, real-time estimation of migration rate using assignment methods: a simulation-based exploration of accuracy and power. Molecular Ecology. 13: 55-65.

Pritchard, JK, M Stephens, and P Donnelly. 2000. Inference of Population Structure Using Multilocus Genotype Data. Genetics. 155: 945-959.

Piry, S, A Alapetite, M Cornuet, D Paetkau, L Baudouin, and A Estoup. 2004. GENECLASS2: A Software for Genetic Assignment and First-Generation Migrant Detection Journal of Heredity. 95(6): 536-539.

Quinn, TP, and DJ Adams. 1996. Environmental changes affecting the migratory timing of American shad and sockeye salmon. Ecology 77, 1151-1162. Raymond M. \& Rousset F, 1995. GENEPOP (version 1.2): population genetics software for exact tests and ecumenicism. Journal of Heredity. 86: 248-249.

Rannala, B and JL Mountain. 1997. Detecting immigration by using multilocus genotypes. Proceedings of the National Academy of Science. 94: 9197-9221.

Raymond ML and F Rousset. 1995. An exact test for population differentiation. Evolution. 49: 1280-1283.

Read, J, BA Manny. 2006. Monitoring element of the Belle Isle/ Detroit River Sturgeon Habitat 
Restoration, Monitoring, and Education Project. Research completion report to Michigan Sea Grant Program, Univ. of Michigan, Ann Arbor, MI. pp. 85.

Rice, W.R. 1989. Analyzing tables of statistical tests. Evolution. 43:223-225.

Roseman, EF, BA Manny, J Boase, M Child, GW Kennedy, J Craig, K Soper, R Drouin. 2011. Lake sturgeon response to a spawning reef constructed in the Detroit River. Journal of Applied Ichthyology. 27: 66-76.

Saint-Laurent, R, M Legault, and L Bernatchez. 2003. Divergent selection maintains adaptive differentiation despite high gene flow between sympatric rainbow smelt ecotypes. Molecular Ecology. 12: 315-330.

Schwab, DJ, AE Clites. 1986. The effect of wind-induced circulation on retention time in Lake St. Clair. Proceedings of 29th Conference of Great Lakes Research, The International Association for Great Lakes Research.

Stockwell, CA, AP Hendry, and MT Kinnison. 2003. Contemporary evolution meets conservation biology. Trends in Ecology and Evolution. 18: 94-101.

Thomas, MV and RC Haas. 2002. Abundance, age structure, and spatial distribution of lake sturgeon (Acipenser fulvescens) in the St. Clair System. Journal of Applied Ichthyology. 18: 495501 .

Van Doornik, DM, BA Berejikian, LA Campbell. 2013. Gene flow between sympatric life history forms of Oncorhynchus mykiss located above and below migratory barriers. PLOS ONE. 8(11): e79931.

Weir, B, and C Cockerham 1984. Estimating F-statistics for the analysis of population structure. Evolution. 38:1358-1370.

Welsh, AB and B May. 2006. Development and standardization of disomic microsatellite markers for lake sturgeon genetic studies. Journal of Applied Ichthyology. 22: 337-344.

Welsh, AB, T Hill, H Quinlan, C Robinson, and B May. 2008. Genetic assessment of lake sturgeon population structure in the Laurentian Great Lakes. North American Journal of Fisheries Management. 28: 572-591. 


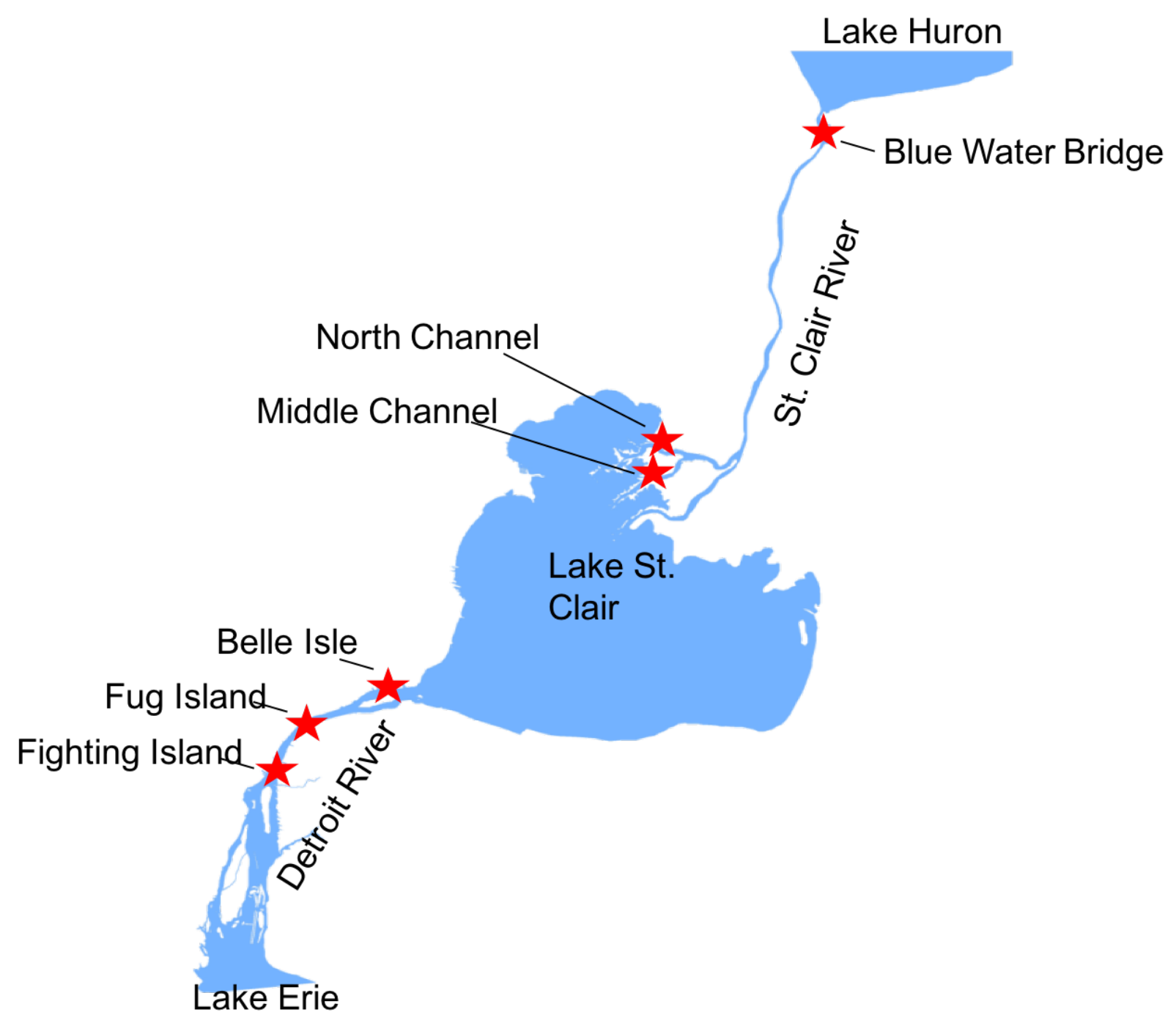

FIGURE 2.1.

The St. Clair-Detroit River System (SCDRS) includes Lake Huron, the St. Clair River, Lake St. Clair, the Detroit River, and Lake Erie. The red stars indicate the location of spawning sites within the SCDRS. 


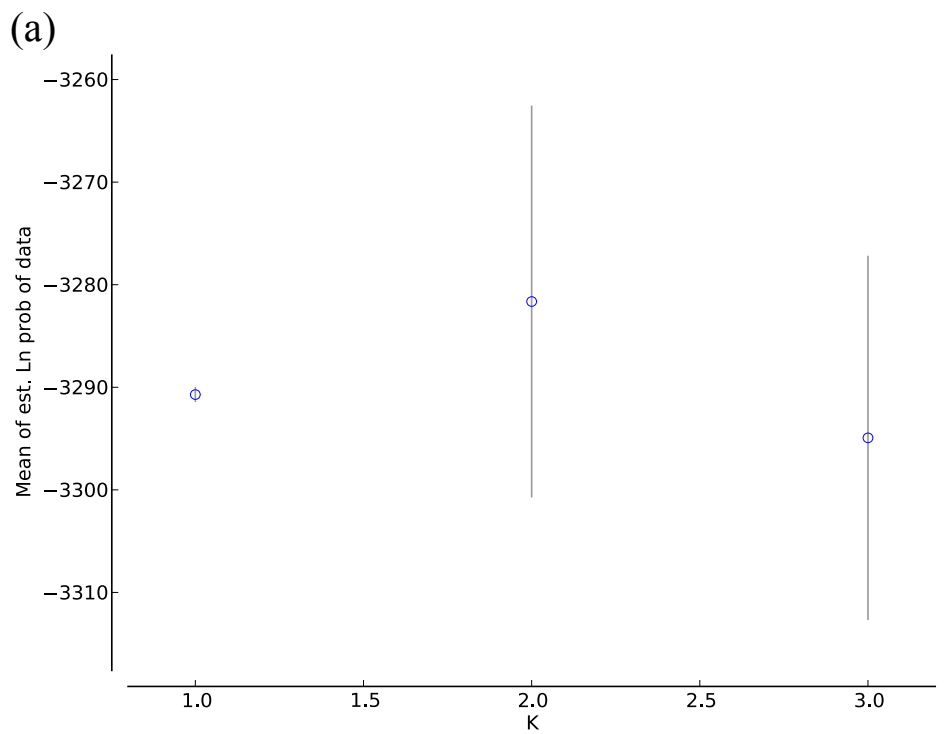

(b)




(c)

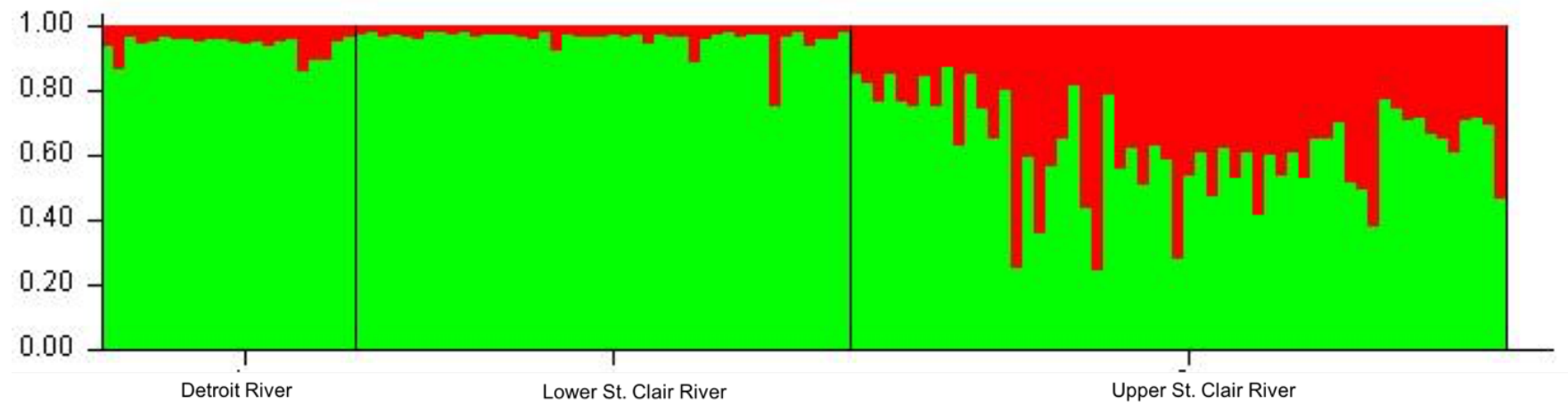

(d)

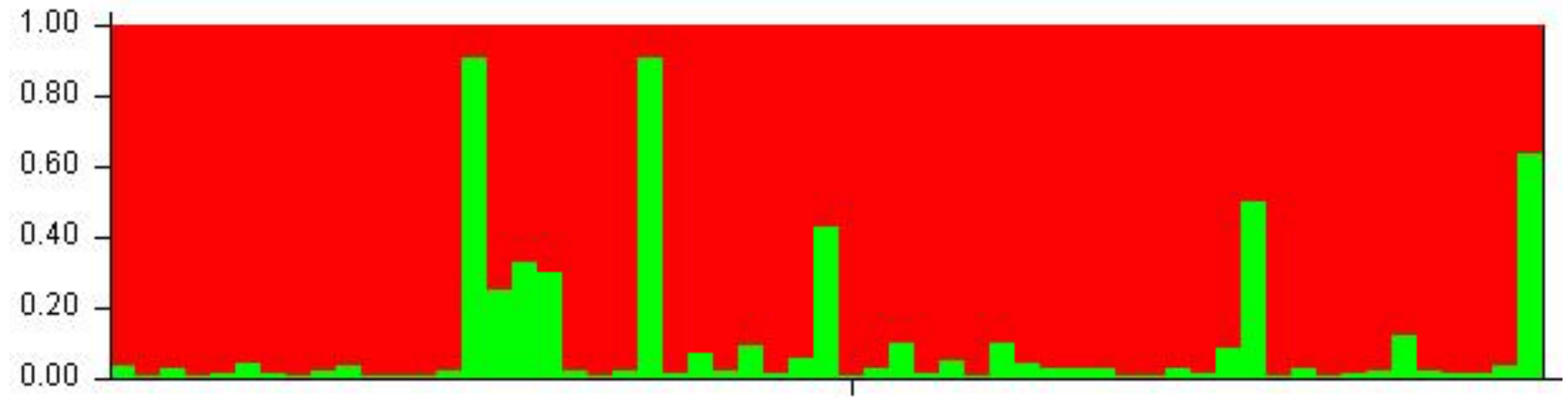

FIGURE 2.2.

An iterative clustering analysis performed using a Bayesian approach implemented in the software program, STRUCTURE was used to produce these results. In panel (a) and (b), the natural-log likelihood values were plotted against possible values of K. Values of K were tested for 1-5 and the most likely value was chosen based on the highest likelihood and lowest variation. In (a), the analysis was performed on all samples $(\mathrm{n}=121)$ and results suggest that $\mathrm{k}=2$ is the most likely number of populations. The analysis was repeated on the upper St. Clair River samples $(\mathrm{n}=56)$. These results suggest that $\mathrm{k}=2$ is the most likely number of populations in the upper St. Clair River. In panels (c) and (d), the plots generated by the program STRUCTURE are provided. In (c), the analysis was performed on all samples $(n=121)$. The Detroit and lower St. Clair appear to be one population, but the upper St. Clair has structure indicating gene flow from a second population. The analysis was repeated on only the samples from the upper St. Clair $(n=56)$. Again, there appears to be migrant gene flow, creating population structure that may be due to migrants from an outside population. 




FIGURE 2.3.

A Discriminant Analysis of Principal Components (DAPC) was performed using the adegenet package in $\mathrm{R}$ to identify variation in genotypes among population locations (Jombart, 2008). This plot provides a visualization of the location of the individuals and clusters in the first two axes of the DAPC space. 1= Detroit River $(n=22), 2=$ Lower St. Clair River $(n=43)$, and 3= Upper St. Clair River $(n=56)$. The points represent individuals and the ellipses represent clusters, which overlap, but do show some clustering. 


\begin{tabular}{ccc}
\hline & Detroit & Lower St. Clair \\
\hline Detroit & & \\
Lower St. Clair & $0.006(0.88)$ & \\
Upper St. Clair & $0.0076(0.55)$ & $\mathbf{0 . 0 1 3 5 ( \mathbf { 0 . 0 2 } )}$ \\
\hline
\end{tabular}

\section{TABLE 2.1}

The $F_{\text {ST }}$ values were generated using the program FSTAT 2.9.3.2 (Goudet, 1995), which implements the method outlined in Weir and Cockerham (1984). The bolded $F_{\text {ST }}$ value was statistically significant $(\alpha=0.05)$; corresponding $p$-values are in parentheses. $F_{\text {ST }}$ values greater than 0.05 are considered to be substantial differentiation. 


\begin{tabular}{ccc}
\hline & Putative Population of & \\
Assigned sample & Origin & Probability \\
\hline USCR27235 & St. Clair River & $77.40 \%$ \\
USCR27238* & Nippissing River & $15.20 \%$ \\
USCR27240 & St. Clair River & $74.50 \%$ \\
USCR29304 & Nippissing River & $75.20 \%$ \\
USCR29310 & Nippissing River & $26.20 \%$ \\
\hline
\end{tabular}

TABLE 1.2

This table lists the five migrants that were identified $(\mathrm{p} \leq 0.05)$ using the Bayesian method implemented in the software program, GeneClass 2 . The asterisk denotes the one migrant that was identified by both GeneClass2 and STRUCTURE. Four Lake Huron populations (Mississagi $(\mathrm{n}=52)$, Nippising $(\mathrm{n}=75)$, Spanish $(\mathrm{n}=47)$, and St. Clair $(\mathrm{n}=50)$ rivers) were used as baseline data to identify putative populations of origin. 


\section{Chapter 3. Characterizing the Migratory Phenotype of Lake Sturgeon Introduction}

Movement is paramount to survival for many species, is nearly ubiquitous across taxa (Alerstam et al., 2003), and may include more specialized forms of movement such as migration and dispersal (Dingle, 2014). Species move for a variety of reasons, including reproduction, resource availability and habitat preference. Simply having the physiological capability to move does not ensure a species will successfully move to avoid environmental impacts, such as global climate change (Feder et al., 2010). Characterizing movement patterns of imperiled species may have important implications for how those species are managed in the face of a changing environment.

A combination of external cues, physiological factors, and genomics has been shown to play a role in determining the movement patterns of species (Dingle, 2014; Liedvogel et al., 2011). Migration, a specialized movement pattern, defined (in some disciplines) as a bidirectional movement to and from a breeding or spawning site, is considered a threshold trait, where environmental and molecular factors reach a threshold before flipping a "switch," (Pulido et al., 1996), causing the initiation of movement. Partial migration, or the existence of both resident and migratory individuals within a population, is a movement pattern that exists in many taxa, including mammals, reptiles, birds, and fish (Ball et al., 2001; Hatase et al., 2013; Lundberg, 1988,). Due to the complexity and ubiquity of migration, a variety of methods, including telemetry, genetics, isotopes, morphometrics and modeling (Lopes et al., 2008, Ostergren et al., 2012) have been used to investigate movement patterns in an integrative approach.

A great deal of research has been performed on salmonids to understand their complex 
migratory behavior, establishing a genetic cause for variation in migratory phenotypes (Hale et al., 2013; Hecht et al., 2012 ; Hecht et al., 2015; LeBras et al., 2011; Nichols et al., 2007). Microsatellites have been used to differentiate populations with varying migratory behaviors in juvenile Sockeye salmon (Oncorhynchus nerka) (Beacham et al., 2014) and Chinook salmon (O. tshwytscha) (Tucker et al., 2012). Similarly, single-nucleotide polymorphisms (SNPs) have been analyzed in juvenile Sockeye salmon and when repeated over three years, migratory routes of juveniles proved to be stable and heritable, despite stochastic ocean environments (Seeb et al., 2011). In cases where there was no evidence for differentiation of runs using microsatellites, the timing of migration of runs of Chinook salmon has been linked to polymorphisms in the OtsClock1b and Ots515NWFSC genes (O’Malley et al., 2013). Pink salmon (O. gorbuscha) have a decrease in the frequency of a late-migration marker, resulting in migration occurring two weeks earlier than it did over 40 years ago (Kovach et al., 2012). These studies suggest evolution is occurring via natural selection as the populations adapt to a changing environment, resulting in local adaptation of the genes associated with migration.

Alternatively, species may respond via phenotypic plasticity, which has been credited with producing migratory phenotypes in fish (Baerwald et al., 2015; Dodson et al., 2013; Hayes et al., 2012). Phenotypic plasticity provides an opportunity for organisms to acclimate in a short time frame (Dolinoy et al., 2007; Gao et al., 2010; Harrisson et al., 2014). This is an alternative to natural selection for surviving in a stochastic environment, which can have an impact on how the genome is translated into a complex phenotype. For example, within white muscle cells of sockeye salmon, transcriptional shifts were detected across the genome due to environmental cues encountered during migration (Miller et al., 2009). Through field observations and 
simulations, masu salmon (O. masou) were shown to exhibit highly plastic migration behaviors, impacted by temperature fluctuations (Morita et al., 2014).

Insight into phenotypic control can also be gained by analyzing the epigenetic mechanisms involved in regulation of gene expression, including methylation, chromatin remodeling, and deacetylation. Methylation, the most widely studied mechanism (Jaenisch and Bird, 2003), has been shown to be involved in the control of phenotypes ranging from Xchromosome inactivation (Heard and Disteche, 2006) to coat color in mice (Morgan et al., 1999) to the ability of species with low genetic variation to invade an unexploited niche (Schrey et al., 2012). In Onchyrnchus mykiss, 57 differentially methylated, migration-related regions were identified between migratory phenotypes (Baerwald et al., 2015). Epigenetic studies can provide insight into complicated phenotypes that are reliant upon both molecular and environmental elements.

A commonly used protocol for studying genome-wide methylation in non-model organisms, specifically those without a reference genome, is the methylation-sensitive amplified fragment length polymorphism (MS-AFLP) protocol. This method is a cost-effective approach that employs methylation sensitive restriction enzymes to produce an individual fingerprint. Of particular benefit, this protocol can be used to determine genome-wide methylation patterns of a large sample size simultaneously (Schrey et al., 2013). It has been used to understand ecologically significant phenotypic variation in wild populations, including both plant and animal taxa (Herrera and Bazaga, 2011; Herrera et al., 2012; Massicotte et al., 2011; Richards et al., 2012).

In most populations of the Great Lakes, lake sturgeon (Acipenser fulvescens) are considered migratory, returning to the lake after spawning in the rivers. However, some 
populations are considered river residents, such as the population in the Kaministiqua River (Friday and Chase, 2005). The St. Clair-Detroit River system (SCDRS) population is partially migrant, with both migratory and river residents occurring in the same population (Boase et al., 2011; Thomas and Haas, 2002). A radio-telemetry study conducted during 1997-1999 in the lower St. Clair River suggested that more than $20 \%$ of tagged individuals were year-round river residents (Boase et al., 2011). Conversely, some lake sturgeon tagged in the St. Clair River have been recorded moving as far as Green Bay, WI and Sandusky Bay, OH (J. Boase, unpublished data), showing the vast difference in movement patterns within the population. The SCDRS is an exceptional study site because the occurrence of alternative life-history traits within one population offers the opportunity to examine these migratory phenotypes while controlling for the effects of environment.

Anecdotal evidence has suggested that there may be morphological differences between river residents and lake migrants of the SCDRS. Morphometrics and meristics have been used to distinguish species and identify hybrids and intraspecific variation in sturgeon (Bakhshalizadeh et al., 2013; Costa et al., 2006; Guenette et al., 1992; North et al., 2002; Vasil'eva, 2009; Walsh et al., 2001; Wills et al., 2002). Some of the commonly used characteristics for morphometric studies of sturgeon are: scute number; shape of gill rakers; size and shape of the mouth; length of the snout; position, number and morphology of the barbels; length of body; and the position and size of fins (Costa et al., 2006; Guenette et al., 1992; North et al., 2002; Ruban, 1989; Vasil'eva, 2009; Walsh et al., 2001). In some cases, morphological data have been combined or contrasted with genetic data to look for differences in how the methodologies delineate populations and species (Artyukhin et al., 2006; Dillman and Hilton, 2011; Walsh et al., 2001). In the case of lake sturgeon, morphometrics were used to identify shortnose sturgeon (Acipenser brevirostrum) as 
the closest relative to lake sturgeon, and this was validated by molecular data (Birstein et al., 1997; Choudhury and Dick, 2003; Dillman and Hilton, 2011).

Marked differences in movements or habitat use may be associated with differences in morphometrics, creating phenotypically different stocks in one system. In fish populations that exhibit subpopulation structure and site fidelity, morphological differences correlate with differences in diet, predation, and habitat (Solem and Berg, 2011). Lake sturgeon have been shown to vary morphometrically when living in different river systems (Ruban and Sokolov, 1986) and in different branches within the same river (Guenette et al., 1992); those differences can be attributed to subtle environmental variation, such as water temperature or current velocity (Ruban and Sokolov, 1986). Guenette et al. (1992) showed that the more sedentary population of lake sturgeon in Lac des Deux Montagnes was morphologically distinct from other populations of lake sturgeon in the St. Lawrence River. Morphometrics could vary between lake sturgeon with different migratory phenotypes in the SCDRS to accommodate the differing life histories. A river resident life history may result in a more streamlined body due to the higher velocity of the water flow. Alternatively, it is plausible that a migratory life history, which requires moving a longer distance to reach the lakes, might have a more streamlined body to physiologically accommodate the longer route traveled. The reverse may also hold true, where a less streamlined body type may benefit a less mobile individual.

The overall goal of this study was to use an integrative approach to characterize the migratory phenotype in lake sturgeon. Our objectives were to: 1) determine whether the lake sturgeon of the St. Clair system differ morphometrically due to variation in migratory phenotypes, 2) determine if individuals with different migratory phenotypes are reproductively isolated, and 3) determine if migratory and river resident individuals are differentially 
methylated, indicating epigenetic differences between the two phenotypes. In contrast to previous movement studies that have relied on telemetry and morphometrics alone to study migration, our study combines these methods with genetic and epigenetic techniques to provide a more comprehensive assessment of intra-population variation in species migration.

\section{Materials and Methods}

Study Site

The SCDRS, a part of the Great Lakes, consists of two major lakes and a river corridor connecting them (Figure 3.1). There is little fluctuation in flow and there are stable changes in temperature throughout the year. Lake Huron is approximately 230 meters deep and temperatures can vary from about $0^{\circ} \mathrm{C}$ to over $25^{\circ} \mathrm{C}$. Lake Erie is shallow, and is the warmest of the Great Lakes (Letcher et al., 2015). The corridor connecting the two lakes consists of the St. Clair River, Lake St. Clair, and the Detroit River. The St. Clair River, which is 64 kilometers long, connects Lake Huron and Lake St. Clair (Boase et al., 2011). Depths in the river range from 8-24 meters, and velocities vary (Edsall et al., 1988), with the highest velocity occurring around the International Blue Water Bridge. Lake St. Clair is, on average, about 3 meters deep and has a short retention time of water, functioning similarly to a shallow river (Schwab and Clites, 1986; Thomas and Haas, 2002). The Detroit River, which is 51 kilometers long, connects Lake St. Clair with Lake Erie (Caswell et al., 2004). The corridor (consisting of Lake St. Clair, and the St. Clair and Detroit rivers) form an important shipping channel connecting the upper and lower Great Lakes. Sediment removal, as much as 46 million $\mathrm{m}^{3}$ from the Detroit River, and shipping channel construction has contributed to the degradation of the fish habitat within the SCDRS (Bennion and Manny, 2011); however, there are no dams within the SCDRS. 


\section{Sturgeon capture and tagging}

Lake sturgeon were captured during May-June from 2011-2015 as part of population surveys conducted by the Michigan Department of Natural Resources in the lower St. Clair River and by the U.S. Fish and Wildlife Service in the upper St. Clair River. Sturgeon collections were supplemented with fish captured by commercial fishermen in southeast Lake Huron approximately $15 \mathrm{~km}$ NNE of the Blue Water Bridge. Most lake sturgeon were captured using baited set lines deployed from a research vessel in the afternoon and retrieved the following morning (Thomas and Haas, 2002). Sturgeon supplied by commercial fisherman were collected as bycatch in trapnets. Acoustic tagging was performed as part of a large collaborative study on lake sturgeon population structure led by the U.S. Geological Survey and Michigan State University. Between 2011 and 2015, a total of 206 adult lake sturgeon (total length 120-180 cm) from the St. Clair River and Lake Huron were surgically implanted with a Vemco 69 kHz V166L acoustic tag. The V16-6L tags had a 10-year battery life, were $16 \mathrm{~mm}$ in diameter, $95 \mathrm{~mm}$ long, and weighed $34 \mathrm{~g}$ in air. Total length (nearest $\mathrm{cm}$ ) and wet weight were recorded for each individual (Table 3.1). Sex was determined only for about $25 \%$ of acoustic-tagged individuals, as North American sturgeon are difficult to sex unless captured in spawning-ready condition. Acoustic-tagged lake sturgeon captured in the St. Clair River were released within $1 \mathrm{~km}$ of the capture site. Trapnet-caught individuals were released in the upper St. Clair River above the Blue Water Bridge. Additional details on surgical procedures and methods can be found in Hondorp et al. (2015).

Acoustic monitoring network and acoustic data filtering

Movements of acoustic-tagged lake sturgeon were monitored on a network of 540 Vemco $69 \mathrm{kHz}$ VR2W receivers deployed throughout Lake Huron, SCDRS, and Lake Erie. A total of 
113 receivers were deployed in the SCDRS and Lake Huron specifically for this project. The Great Lakes Acoustic Telemetry Observation System (GLATOS) provided data from an additional 432 receiver sites (www.data.glos.us/glatos/). Each acoustic receiver records the date, time, and unique ID code for each acoustic tag detection. Most receivers were recovered, downloaded, and replaced twice per year (spring and fall).

Acoustic detection data were downloaded from each recovered receiver using Vemco VUE software. Raw data files were uploaded to a central database maintained by GLATOS, which then provided a complete detection history for each acoustic-tagged lake sturgeon. Suspected false positives in individual detection histories were identified and removed following the methods detailed in Hondorp et al. (2015).

The migratory phenotype (resident or migrant) of individual fish was determined by using the telemetry data collected from 2012-2015. Fish were coarsely categorized as a resident or migrant based on habitat use data, which details the proportion of time a fish spent in each habitat (Table 3.1). Of the 63 fish categorized, 57 spent greater than $90 \%$ of their time in either the corridor (St. Clair River, Lake St. Clair, Detroit River) or in Lake Huron. The remaining 6 fish resided in one of the two habitats for $63-87 \%$ of the time (Table 3.1). When the phenotype was not clear, movement patterns were clarified using visual observation via time plots. Very few telemetered fish entered Lake Erie, and none of the fish included in subsequent analyses migrated to Lake Erie. Based on differences in depth, temperature, and productivity from Lakes Huron and Erie, Lake St. Clair was determined to be more similar to the rivers in this system than the lakes; therefore, it was included as river resident habitat.

\section{Morphometrics}


Digital photographs (1.5 to 2.8 megapixel resolution images) of 63 telemetered fish (27 migrants, 38 residents) were used to obtain measurements of 18 morphological features. Photographs were taken during spawning season (April - June) in 2012 and 2013. Three views of the fish were photographed: dorsal, ventral and lateral, from approximately four feet, directly above the fish in the dorsal and ventral views, and from the side of the fish in the lateral views. Photographs of the tail and total body were taken from the lateral view only. Linear measurements taken from the ventral view were: barbels to mouth, width of the gape, head length, and the length of the pectoral fin. The following measurements were taken from the dorsal view photographs: width of the head between the eyes, width of the head between the opercula, head length from the rostrum to the opercula, pectoral fin length. The length from the rostrum to the nare, length from the nare to the eye, eye diameter, and pectoral fin length were measured from the lateral view photographs. For the close up of the lateral view of the tail, the following measurements were taken: length of the upper portion of the caudal fin (from fork to tip), length of the lower portion of the caudal fin, width of the peduncle, and the length of the dorsal fin. Lastly, the length of the entire fish was taken. A ruler was placed on each fish so that scale and image measurement could be calibrated for each photograph. Landmarks were identified using a modified method based on that of Guenette et al. (1992). Linear measurements were taken between identified landmarks using the software ImageJ version 1.50c (Abramoff et al., 2004). Principal component analysis (PCA) was performed with R software (Package: MASS, cran mirror: USA PA1) and was used to identify variation among the morphometric measurements taken.

\section{Genetic Differentiation}


DNA was extracted from 41 fin clips (a subset of the 63 individuals used in the morphological analysis) (22 migrants and 19 residents) using the Qiagen PureGene Genomic DNA Purification Kit ${ }^{(}$(Germantown, MD, USA) and quantified on the Nanodrop ${ }^{\circledR}$ (ThermoScientific, Wilmington, DE, USA). Extracted DNA was analyzed at 11 microsatellite loci: AfuG9, AfuG56, AfuG63, AfuG68, AfuG74, AfuG112, AfuG160, AfuG195, AfuG204, Aox27, and Spl120 (Welsh and May, 2006). PCR amplification was done using the Qiagen Multiplex PCR Kit ${ }^{(}$(Germantown, MD, USA). Four primer mixes were prepared. Primer mix 1 (AfuG 56, Spl120 and AfuG 195), primer mix 2 (AfuG204, AfuG74, and AfuG9), and primer mix 3 (AfuG160, Aox27 and AfuG112) contained $2 \mu \mathrm{M}$ final concentration of each primer. Primer mix 4 included Afu68 primers (final concentration of $1 \mu \mathrm{M}$ ) and AfuG63 primers (final concentration of $2 \mu \mathrm{M}$ ). The Mulitplex PCR Master Mix (final concentration of 1X) was used in a total reaction volume of $10 \mu 1$, with 20 ng of extracted DNA. The PCR conditions for primer mix 1 were $95^{\circ} \mathrm{C}$ for 15 minutes; 15 cycles of $94^{\circ} \mathrm{C}$ for 30 seconds, $60^{\circ} \mathrm{C}$ for 90 seconds with a $0.5^{\circ}$ decrease with each cycle, $72^{\circ} \mathrm{C}$ for 60 seconds; 15 cycles of $94^{\circ} \mathrm{C}$ for 30 seconds, $52^{\circ} \mathrm{C}$ for 90 seconds, $72^{\circ} \mathrm{C}$ for 60 seconds; $60^{\circ} \mathrm{C}$ for 30 minutes. The PCR conditions for primer mixes $2-4$ were $95^{\circ} \mathrm{C}$ for 15 minutes; 35 cycles of $94^{\circ} \mathrm{C}$ for 30 seconds, $57^{\circ} \mathrm{C}$ for 90 seconds, $72^{\circ} \mathrm{C}$ for 60 seconds; $60^{\circ} \mathrm{C}$ for 30 minutes. PCR products were then visualized on a Beckman Coulter GeXP Genetic Analysis System.

\section{Statistical Analysis}

Based on the resulting microsatellite genotypes, analyses were conducted to determine the most likely number of populations in the SCDRS. A Bayesian approach for population clustering was performed using the software STRUCTURE (Pritchard et al., 2000), which estimates the likelihood of population clusters based on Hardy-Weinberg equilibrium (HWE) and 
linkage disequilibrium. A burn-in length of 100,000 and 100,000 MCMC steps were used for 10 iterations under the admixture model. It was assumed that the allele frequencies were correlated. The migratory phenotype, determined from telemetry data, was used as prior knowledge. Values of $\mathrm{K}$ were tested for $\mathrm{K}=1-5$ and the most likely value was chosen based on the highest likelihood and lowest variation. HWE was tested for each locus and population using the software GENEPOP 4.2 (Raymond and Rousset, 1995), which utilizes an exact probability test estimated by Markov chain algorithms. The following parameters were used: 10,000 burn-in, 100 batches, 1,000 iterations, and $\alpha \leq 0.05$. Significance of the HWE tests was determined after performing a sequential Bonferroni correction (Rice, 1989). Linkage disequilibrium was tested for pairs of loci using probability tests, via GENEPOP 4.2 (Raymond and Rousset, 1995). A burn-in length of 10,000 was used for 100 batches and 1,000 iterations. The $F_{\mathrm{ST}}$ value between the two phenotypes was calculated using the program FSTAT 2.9.3.2 (Goudet, 1995), which implements the method outlined in Weir and Cockerham (1984), to determine if the two groups were genetically distinct $(\mathrm{p} \leq 0.05) . F_{\mathrm{ST}}$ values range from 0 to 1 and larger numbers correspond to increased genetic differentiation.

\section{Differential Methylation}

DNA was also extracted from 41 blood samples (22 migrants and 19 residents) using the GeneJET Genomic DNA Purification Kit (Life Technologies, Carlsbad, California, USA) and quantified on the Nanodrop ${ }^{\circledR}$ (ThermoScientific, Wilmington, DE, USA). The 41 blood samples were from the same individuals genotyped for the microsatellite analysis described above. The MS-AFLP protocol was performed as described in Schrey et al. (2012) with the modification that ligation and digestion were performed in one step. In addition to the digestion reagents, the 
master mix for the digestion/ligation step included 1.3X T4 DNA Ligase Buffer (Thermo Fisher Scientific) and 1.3U T4 DNA Ligase (Thermo Fisher Scientific). Selective PCR products were visualized on a Beckman Coulter GeXP Genetic Analysis System. The protocol was performed with $25 \%$ random duplication of samples to validate individual results. Any results that could not be validated were removed from analysis. Data were scored for individuals in the manner described in Schrey et al. (2012). Each restriction site was identified as being either methylated or unmethylated, resulting in an epi-genotype for each individual.

\section{Statistical Analysis}

To identify whether there was differential methylation between the migratory phenotypes based on the MS-AFLP data, an AMOVA was performed using GeneALEx 6.5 (Peakall and Smouse, 2012) on the total restriction sites as well as for each individual restriction site, with 9999 permutations and $\alpha \leq 0.05$. BayeScan 2.1 (Foll and Gaggiotti, 2008) was used to identify sites that may be under selection, by analyzing patterns of differentiation in allele frequencies that diverged from neutral expectations. Prior odds for the neutral model were set to 10:1. The program was run with 20 pilot runs at a length of 5,000 for 5,000 iterations. The burn-in (following the pilot runs) was 50,000 iterations, and the thinning interval was set to $10 . \mathrm{F}_{S T}$ values ranged from 0 to 1 and an $\alpha \leq 0.05$ was considered to be significant. If the alpha value was positive, the selection is considered to be diversifying, whereas if the alpha was negative, then the selection is considered to be balancing or purifying. Model choice was performed using Bayes Factors, which were calculated for the individual restriction sites.

\section{Results}




\section{Morphometrics}

Lake sturgeon classified as migrants and residents did not differ morphologically based on the measurements taken in this study. Results from a principal component analysis (PCA) on the 18 measurements taken on sampled fish did not support morphological differences between migrants and river residents in the SCDRS, as depicted in the PCA plot (Figure 3.2). The total of the first three principal components accounted for $58 \%$ of variation. PC1 explained $29.9 \%$ of the variance in the matrix while PC2 explained $14.7 \%$ of the variance. PC1 represented a head gradient because the measurements for head length and width had high positive factor loadings (Table 3.2). PC2 may also represent a head gradient because the snout measurement had a high positive factor loading, but tail measurements, including the width of the peduncle and the length from the fork to the tip of the upper tail had high negative factor loadings. The PCA showed that fish length was not responsible for any variation in the measurements taken on migratory and resident fish, likely because fish length did not vary greatly between fish sampled.

\section{Genetic Differentiation}

The migratory phenotypes did not show evidence of being reproductively isolated. Based on the results of the STRUCTURE analysis, there is only one population $(\mathrm{K}=1)$ (Figure 3.3). The $F_{S T}$ value calculated to determine genetic differentiation between migratory phenotypes was $0.0148(\mathrm{p}=0.11)$ which is interpreted as no genetic differentiation between the two groups. After a sequential Bonferroni correction, no loci were deemed to be out of HWE and there was no evidence of linkage disequilibrium at any loci.

\section{Differential Methylation}

The MS-AFLP protocol resulted in the identification of 89 restriction sites. The AMOVA, 
when performed across all restriction sites, identified significant differences in methylation between the migratory and resident groups $(\mathrm{p}=0.001)$ (Tables 3.3 and 3.4). Additionally, when analyzed at the individual restriction sites, 13 sites were statistically different (Table 3.4). Out of the 13 sites, 8 had higher proportions of methylation in the migratory group. None of the methylation differences appeared to be due to selection (Bayes factors $<1$ ).

\section{Discussion}

Migration is a complex behavior, required for survival by many species, but the molecular component to migration is still not well understood. Furthermore, even less is known regarding the epigenetics involved in complex traits of non-model organisms from wild populations. We used an integrative approach that included morphometrics, genetics, and epigenetics to characterize the migratory phenotypes of lake sturgeon in the SCDRS.

Given that we were unable to detect morphological differences between migratory phenotypes, migration may not be a selective force in creating morphological differences in lake sturgeon of the SCDRS. However, further analyses may be warranted. Although there were no morphological differences between migratory phenotypes based on the measurements taken in this study, these were linear measurements taken from photographs. As opposed to linear measurements, geometric morphometrics uses at least three landmarks to identify a shape, providing more information about the curves, outlines, and surface (Zelditch et al., 2004). Performing a geometric morphometric analysis may provide finer resolution, possibly identifying undetected morphological differences. In addition to a geometric analysis, the cumulative telemetry data that will be collected over the years may provide refined insight into the movement patterns and create a more rigorous method of determining the migratory 
phenotype. For instance, there is a subset of the population that spawns near the mouth of the St. Clair River, and then moves downriver (Boase, James, personal communication). This is a different life history than the typical migration pattern where the fish would move back out into Lake Huron. By repeating the analyses with more telemetry data and thus more refined groupings, morphometric differences may be revealed. Lastly, there may also be unexplored variables that would explain the possible variation in morphology. For instance, differences in habitat, diet, predation, water temperature and velocity all may have an impact on morphometrics (Ruban and Sokolov, 1987; Guenette et al., 1992; Solem and Berg, 2011).

The microsatellite data suggest that there is gene flow between migratory phenotypes. However, increased sample size may be required to detect population structure. Additionally, it is plausible that while lake sturgeon in the SCDRS are not showing genetic differences at neutral markers, there may be adaptive genetic variation due to variations in the environment. Adaptive markers have been used to identify spatially varying selection occurring in the presence of gene flow (Hemmer-Hansen et al., 2013; O’Malley et al., 2013; Pujolar et al., 2014). Adaptive markers may be found throughout the genome, as is the case in the European eel (Anguilla anguilla), despite being a panmictic population (Pujolar et al., 2014). However, in other cases the markers are found in genomic islands, as in Atlantic cod (Gadus morhua), where migratory phenotypes were differentiated by a genomic region of about $20 \mathrm{cM}$, suggesting that there may be a divergence occurring between these ecotypes despite the lack of differentiation at neutral markers (Hemmer-Hansen et al., 2013). Identification of adaptive genes related to migration in lake sturgeon might provide evidence for natural selection in the SCDRS. However, in our analysis of differentially methylated sites, there were no restriction sites found to be undergoing 
selection, which suggests that this is a highly plastic trait, possibly controlled through epigenetics.

The epigenetic data, suggest that the different migratory phenotypes may not due to a genetic change, but instead may be due to an epigenetic difference. MS-AFLPs, which measures genome-wide methylation, were used to detect differential methylation between the phenotypes. These findings suggest that, while there is no evidence for a genetic explanation for the differences noted in migratory phenotypes, there may be epigenetic differences. It is not currently known whether these differentially methylated sites fall within gene regions relevant to migration. A more sensitive approach, such as bisulfite sequencing, would provide higher resolution and is known to be more sensitive, possibly revealing an even greater role of methylation in the generation of migratory phenotypes.

Within fisheries, migratory phenotypes have been best studied in salmonid species. In contrast to this study, a genetic component has been confirmed in some species (Hale et al., 2013; Hecht et al., 2012; Hecht et al., 2013; LeBras et al., 2011; Nichols et al., 2007). However, in addition to being a heritable trait, migratory phenotypes in salmonids are also influenced by the environment (Sloat et al., 2014). Maintaining flexibility in life history strategies can be beneficial in a stochastic environment. Studies of salmonid species have shown that methylation plays an important role in complicated traits, such as transition to marine environments (Moran et al. 2013) and early maturation (Moran and Perez-Figueroa, 2011). In sturgeon, migration is linked to reproduction. Spawning of lake sturgeon occurs in the spring and early summer, and is dependent upon environmental cues, such as photoperiod (Bizzotto et al., 2009; Quinn and Adams, 1996) and water temperature (Forsythe et al., 2012), and is predictable from year to year (Forsythe, 2010; Forsythe et al., 2012). An alteration in methylation could be the result of a 
changing environment or a possible method of acclimating to a new environmental cue, which could be relevant due to anthropogenic changes that have occurred in the SCDRS. A plastic phenotype would allow an individual to move at a time that is most beneficial for spawning based on environmental cues, or it might cause an individual to skip a year based on internal physiological cues. Both types of cues could spur a cascade of molecular events leading to epigenetic mechanisms altering transcription of relevant proteins involved in the most beneficial migratory phenotype. Studies on $O$. mykiss have shown that differential methylation may be the means of creating phenotypic plasticity in complex morphological traits related to migration (Baerwald et al., 2015). It is plausible that the migratory phenotypes are a plastic trait that can be altered based on the environment, depending on what is best suited for that spawning season.

Although methylation may play a role in determining migratory phenotypes, the cause of the differential methylation remains unclear. It is possible that as the migrants move out of the rivers to feed, they are feeding on different organisms than those fish that stay within the rivers year round. Differences in the feeding habitat or food sources could cause a change in the methylation patterns. De novo methylation, where an unmethylated portion of the DNA is methylated, has been shown to be influenced by the environment. For instance, in the case of honey bees, diet determines whether a larvae becomes a fertile queen or a sterile worker. Only larvae meant to be queens are fed royal jelly. When the de novo methylation enzyme is inactivated during a specific duration of honey bee development, de novo methylation does not occur, and the larvae produced are fertile (Kucharski et al., 2008). This provides evidence that environmentally induced methylation is the mechanism for the alternative sterile phenotype and that the royal jelly influences mehtylation, creating fertile queens. In agouti mice, it has been shown that when pregnant mice were fed a diet supplemented with methyl donors, progeny with 
a normal phenotype were produced (Wolff et al., 1998). Additionally, when pregnant agouti mice are exposed to bisphenol-A, which decreases methylation, coat color of the progeny is predominately the mutant color (Dolinoy et al., 2007).

De novo epigenetic marks, environmentally induced or not, may become heritable, especially if they are associated with an adaptive trait. There are two possible ways for epigenetics to cause an impact on the evolutionary potential of a species. If the differential epigenetics impact an ecologically important phenotype and is heritable, then it may be influenced by natural selection, causing evolution over time. To be advantageous, a heritable epigenetic mechanism would need to occur where an environmental change outlasts the generation time of the species, and there would need to be a lag between the environmental change and the phenotypic change, providing time for selection pressure (Lachman and Jablonka, 1996). However, if the epigenetic markers are reversible, this provides an opportunity for a species to acclimate to a stochastic environment in a short time frame, by-passing natural selection (Bossdorf et al., 2008). The coexistence of alternative phenotypes may have evolved as a way for individuals in a population to survive in a changing environment (Debat and David, 2001; Dudley and Schmitt, 1996). Fish that are phenotypically plastic may have increased fitness, resulting in their survival and subsequent reproduction. In this way, plasticity drives evolution.

It is possible that the migratory phenotype is a plastic trait that is not heritable, but instead provides a mechanism to acclimate to changing environmental conditions. Since none of the restriction sites identified appeared to be under selection, this may be the case for lake sturgeon in the SCDRS. However, identification of outlier loci, using programs such as BayeScan, is dependent upon an assumption that adaptation is due to a "selective sweep," 
defined as a significant change in frequency of an allele in a population (Pritchard and Di Rienzo, 2010). It is possible that this type of analysis is insufficient in identifying outlier loci in certain situations, such as when the phenotype is due to a suite of genes with each gene only having a small effect (Brieuc et al., 2015). Migration is a complicated phenotype that may involve genes ranging from 'clock' genes affecting the timing of migration to genes related to metabolism, navigation and immunity. A polygenic adaptation may not require a large effect to create a change in the phenotype, but may instead be due to a small change in allele frequency of a few genes, which could be undetectable by current outlier analyses (Pritchard and DiRenzo, 2010). Therefore, when quantifying changes to phenoytpes such as migration, it may be necessary to analyze covarying alleles to elucidate the possibility of adaptation

A consideration when interpreting methylation studies is that the influence that methylation has on DNA is not completely understood. Methylation of DNA typically involves a methyltransferase enzyme adding a methyl group to a $\mathrm{CpG}$ site, which are often found in the regulatory region of a gene. Methylation is known, in some cases, to be associated with decreased expression of a gene. However, this is not always the case. Without knowing how the methylation affects the expression, and which genes are affected, we are unable to determine if the differentially methylated sites can be linked to an adaptive marker relevant to migration. To determine the true effect on a phenotype, a common garden experiment would be required. Controlled experiments have been performed in plants showing that methylation directly interferes with transcription and is involved with the formation of heterochromatin, which can also silence transcription (Jablonka and Raz, 2009; Zilberman and Henikoff, 2007). This is known to affect phenotypes, such as floral symmetry and fruit ripening (Marfil et al., 2009). Applying epigenetics to wild populations is more difficult, but it has been shown that in Viola 
cazorlensis populations, epigenetics plays a role in potentially adaptive traits for different populations by relating differential methylation to population differentiation of ecologically important traits (Herrera and Bazaga, 2010).

The above limitations should be considered when making management recommendations based on epigenetic studies of wild populations. However, further characterization of migratory phenotypes would benefit management of lake sturgeon, especially with regard to potential shifts in movement patterns related to global climate change. Since timing of spawning may be partially temperature dependent, understanding the genetic and epigenetic underpinnings of movement would be crucial to development of an adaptive management plan. As technology continues to advance in the discipline of movement ecology, it is important to incorporate a variety of methods in study designs. In the case of lake sturgeon in the SCDRS, using morphometrics and neutral genetic markers alone would not have been able to differentiate between the migratory phenotypes. However, epigenetic techniques are providing researchers with an additional technique to understanding complex behavioral traits, such as movement patterns. 


\section{References}

Abramoff, MD, PJ Magalhaes, and SJ Ram. 2004. Image Processing with ImageJ. Biophotonics International. 11(7): 36-42.

Alerstam T, A Hedenstrom, and S Akesson. 2003. Long-distance migration: evolution and determinants. Oikos. 103: 247-260.

Artyukhin, EN. 2006. Morphological phylogeny of the order Acipenseriformes. Journal of Applied Ichthyology. 22(1): 66-69.

Ball, J, C Nordengren, and K Wallin. 2001. Partial migration by large ungulates: characteristics of seasonal moose Alces ranges in northern Sweden. Wildlife Biology. 7: 39-47.

Baerwald, MR, MH Meek, MR Stephens, RP Nagarajan, AM Goodbla, KMH Tomalty, GH Thorgaard, B May, KM Nichols. 2015. Special Issue: Epigenetic studies in ecology and evolution. Migration-related phenotypic divergence is associated with epigenetic modifications in rainbow trout. Molecular Ecology. doi: 10.1111/mec.13231

Bakhshalizadeh, S, A Bani, and S Abdolmalaki. 2013. Comparative morphology of the pectoral fin spine of the Persian sturgeon (Acipenser persicus), the Russian sturgeon (Acipenser gueldenstaedtii), and the Starry sturgeon (Acipenser stellatus) in Iranian waters of the Caspian Sea. Acta Zoologica (Stockholm). 94: 471-477. doi:10.1111/j.14636395.2012.00576.x.

Beacham, TD, RJ Beamish, JR Candy, C Wallace, S Tucker, JH Moss, and M Trudel. 2014. Stock-specific migration pathways of juvenile Sockey salmon in British Columbia waters and in the Gulf of Alaska. Transactions of the American Fisheries Society. 143:1386-1403.

Bennion, DH, and BA Manny. 2011. Construction of shipping channels in the Detroit River: history and environmental consequences. U.S. Geological Survey Scientific Investigations Report. 2011-5122.

Bizzotto, PM, AL Godinho, V Vono, B Kynard, and HP Godinho. 2009. Influence of seasonal, diel, lunar, and other environmental factors on upstream fish passage in the Igarapava Fish Ladder, Brazil. Ecology of Freshwater Fish. 18: 461-472.

Birstein, VJ, R Hanner, and R DeSalle. 1997. Phylogeny of the Acipenseriformes: Cytogenetic and molecular approaches. Environmental Biology of Fishes. 48(1-4): 127-156.

Boase, JC, JS Diana, MV Thomas, JA Chiotti. 2011. Movements and distribution of adult Lake Sturgeon from their spawning site in the St. Clair River, Michigan. Journal of Applied Ichthyology. 27(2): 58-65.

Bossdorf, O, CL Richards, and M Pigliucci. 2008. Epigenetics for ecologists. Ecology Letters. 11(2):106-115. 
Brieuc, MO, K Ono, DP Drinan, and KA Naish. 2015. Integration of Random Forest with population-based outlier analyses provides insight on the genomic basis and evolution of run timing in Chinook salmon (Oncrhynchus tshawytshca). Molecular Ecology. 24: 2729-2746.

Caswell, NM, DL Peterson, BA Manny, GW Kennedy. 2004. Spawning by lake sturgeon (Acipenser fulvescens) in the Detroit River. Journal of Applied Ichthyology. 20: 1-6.

Choudhury, A, and TA Dick. 2001. Sturgeons (Chondrostei: Acipenseridae) and their metazoan parasites: Patters and processes in historical biogeography. Journal of Biogeography. 28(11-12): 1411-1439.

Costa, C, E Tibaldi, L Pasqualetto, and A Loy. 2006. Morphometric comparison of the cephalic region of cultured Acipenser baerii (Brandt, 1869), Acipenser naccarii (Bonaparte, 1836) and their hybrid. Journal of Applied Ichthyology. 22: 8-14.

Debat, V, and P David. 2001. Mapping phenotypes: canalization, plasticity and developmental stability. Trends in Ecology and Evolution. 16(10): 555-561.

Dillman, CB, and EJ Hilton. 2011. The cause and effect of polarizaiton: Thoughts on the "Morphological versus Molecular" debate in systematics, with examples from the study of sturgeons (Actinopterygii: Acipenseridae). Zootaxa. 2946: 79-117.

Dingle, H. 2014. Migration: the biology of life on the move. Oxford University Press, New York, NY.

Dodson, JJ, N Aubin-Horth, V Theriault, DJ Paez. 2013. The evolutionary ecology of alternative migratory tactics in sal- monid fishes. Biological Reviews. 88: 602-625.

Dolinoy, DC, D Huang, and RL Jirtle. 2007. Maternal nutrient supplementation counteracts bisphenol A-induced DNA hypomethylation in early development. Proceedings of the National Academy of Science. 104: 13056-13061.

Dudley, SA, J Schmitt. 1996. Testing the Adaptive Plasticity Hypothesis: Density-Dependent Selection on Manipulated Stem Length in Impatiens capensis. The American Naturalist. 147(3): 445-465.

Edsall, TA, BA Manny, CN Raphael. 1988. The St. Clair River and Lake St. Clair, Michigan: an ecological profile. US Fish and Wildlife Service, Biological Report 85(7.3), Slidell, LA.

Feder, ME, T Garland, Jr., JH. Marden, and AJ Zera. 2010. Locomotion in Response to Shifting Climate Zones: Not So Fast. Annual Reviews: Physiology. 72:167-90.

Foll, M, and OE Gaggiotti. 2008. A genome scan method to identify selected loci appropriate for both dominant and codominant markers: A Bayesian perspective. Genetics 180: 977-993.

Forsythe, PS. 2010. External correlates of migratory and spawning activity and egg depo- 
sition and mortality in lake sturgeon Acipenser fulvescens. PhD Thesis, Department of Zoology, Michigan State University. East Lansing, MI, USA.

Forsythe PS, KT Scribner, JA Crossman, A Ragavendran, EA Baker, C Davis, KK Smith. 2012. Environmental and lunar cues are predictive of the timing of river entry and spawning-site arrival in lake sturgeon Acipenser fulvescens. Journal of Fish Biology. 81:35-53.

Friday MJ, and ME Chase. 2005. Biology and management of lake sturgeon (Acipenser fuvescens) in the Kaministiquia River. Ontario ministry of natural resources upper great lakes management unit technical report.

Gao, L, Y Geng, B Li, J Chen, and J Yang. 2010. Genome-wide DNA methylation alterations of Alternanthera philoxeroides in natural and manipulated habitats: implications for epigenetic regulation of rapid responses to environmental fluctuation and phenotypic variation. Plant Cell \& Environment. 33: 1820-1827.

Goudet, J. 1995. FSTAT (Version 1.2): A computer program to calculate F-statistics. Journal of Heredity. 86:485-486.

Guenette, S, E Rasser, and R Fortin. 1992. Morphological differentiation of lake sturgeon (Acipenser fulvescens) from the St. Lawrence River and Lac des Deux Montagnes (Quebec, Canada). Canadian journal of fisheries and aquatic sciences. 49(9): 1959-1965.

Hale, MC, FP Thrower, EA Bernston, MR Miller, KM Nichols. 2013. Evaluating adaptive divergence between migratory and nonmigratory ecoytpes of salmonid fish, Oncorhynchus mykiss. G3 (Bethesda), 3: 1273-1285.

Harrisson, KA, A Pavlova, M Telonis-Scott, and P Sunnucks. 2014. Using genomics to characterize evolutionary potential for conservation of wild populations. Evolutionary Applications. 7(9): 1008-1025.

Hatase, H, K Omuta, and K Tsukamoto. 2013. A mechanism that maintains alternative life histories in a loggerhead sea turtle population. Ecology. 94: 2583-2594.

Hayes SA, CV Hanson, DE Pearse. MH Bond, JC Garza, and RB MacFarlane. 2012. Should I stay or should I go? The influence of genetic origin on emigration behavior and physiology of resident and anadromous juvenile Oncorhynchus mykiss. North American Journal of Fisheries Management. 32: 772-780.

Heard, E, and CM Disteche. 2006. Dosage compensation in mammals: fine-tuning the expression of the X chromosome. Genes and Development. 20(14): 1848-1867.

Hecht BC, NR Campbell, DE Holecek, SR Narum. 2012. Genome-wide association reveals genetic basis for the propensity to migrate in wild populations of rainbow and steelhead trout. Molecular Ecology. 22: 3061-3076.

Hecht BC, JJ Hard, FP Thrower, KM Nichols. 2015. Quantitative genetics of migration related traits in rainbow and steelhead trout. Genes Genomes Genetics. 5: 873-879. 
Hemmer-Hansen, J, EE Nielsen, NO Therkildsen, MI Taylor, R Ogden, AJ Geffen, D Bekkevold, S Helyar, C Pampoulie, T Johansen, and GR Carvalho. 2013. A genomic island linked to ecotype divergence in Atlantic cod. Molecular Ecology. 22: 2653-2667.

Herrera, CM, and P Bazaga. 2011. Untangling individual variation in natural populations: ecological, genetic and epigenetic correlates of long-term inequality in herbivory. Molecular Ecology. 20(8): 1675-1688.

Herrera, CM, MI Pozo, P Bazaga. 2012. Jack of all nectars, master of most: DNA methylation and the epigenetic basis of niche width in a flower living yeast. Molecular Ecology. 21: 2602-16.

Hondrop, DW, CM Holbrook, and CC Krueger. 2015. Effects of acoustic tag implantation on lake sturgeon Acipenser fulvescens: lack of evidence for changes in behavior. Animal Biotelemetry. 3(44). DOI: 10.1186/s40317-015-0085-0.

Jablonka, EVA, and GAL Raz. 2009. Transgenerational epige- netic inheritance: prevalence, mechanisms, and implications for the study of heredity and evolution. Quarterly Review of Biology. 84(2): 131-176.

Jaenisch, R, and A Bird. 2003. Epigenetic regulation of gene expression: how the genome integrates intrinsic and environmental signals. Nature Genetics. 33: 245-254.

Kovach, RP, JE Joyce, JD Echave, MS Lindberg, and DA Tallmon. 2013. Earlier migration timing, decreasing phenotypic variation, and biocomplexity in multiple salmonid species. PLoS ONE. 8: e53807.

Kucharski, R, J Maleszka, S Foret, and R Maleszka. 2008. Nutri- tional control of reproductive status in honeybees via DNA methylation. Science. 319(5871): 1827-1830.

Lachman, M, and E Jablonka. 1996. The inheritance of phenotypes: an adaptation to fluctuating environments. Journal of Theoretical Biology. 181: 1-9.

LeBras, Y, N Dechamp, F Krieg, O Filangi, R Guyomard, M Boussaha, H Bovenhuis, TG Pottinger, P Prunet, P LeRoy, and E Quillet. 2011. Detection of QTL with effects on osmoregulation capacities in the rainbow trout (Oncorhynchus mykiss). Genetics. 12:46.

Letcher, RJ, Z Lu, SR de Solla, CD Sandau, KJ Fernie. 2015. Snapping Turtles (Chelydra serpentina) from Canadian Areas of Concern across the southern Laurentian Great Lakes: Chlorinated and brominated hydrocarbon contaminants and metabolites in relation to circulating concentrations of thyroxine and vitamin A. Environmental Research. 143: 266-278.

Liedvogel, M, S Akesson, and S Bensch. 2011. The genetics of migration on the move. Trends in Ecology \& Evolution. 26: 561-569.

Lopes, R, F Hortas, and L Wennerberg. 2008. Geographical segregation in Dulin Calidris alpina populations wintering along the East Atlantic migratory flyway - evidece from mitochondrial DNA analysis. Diversity and Distributions. 14: 732-741. 
Lundberg, P. 1988. The evolution of partial migration in birds. Trends in Ecology and Evolution. 3: $172-175$.

Marfil CF, EL Camadro, RW Masuelli. 2009. Phenotypic instability and epigenetic variability in a diploid potato of hybrid origin, Solanum ruizlealii. BMC Plant Biology. 9: 21.

Massicotte R, E Whitelaw, B Angers. 2011. DNA methylation: a source of random variation in natural populations. Epigenetics. 6:421-7.

Miller, KM, AD Schulze, N Ginther, S Li, DA Patterson, AP Farrell, SG Hinch. 2009. Salmon spawning migration: metabolic shifts and environmental triggers. Comparative Biochemistry and Physiology. Part D Genomics Proteomics. 4, 75-89.10.1016/j.cbd.2008.11.002

Moran, P, F Marco-Rius, M Megias, L Covelo-Soto, A Perez-Figuroa. 2013. Environmental induced methylation changes associated with seawater adaptation in brown trout. Aquaculture. 392(395): 77-83.

Moran, P, and A Perez-Figueroa. 2011. Methylation changes associated with early maturation stages in the Atlantic salmon. BMC Genetics. 12: 86.

Morita, K, T Tamate, M Kuroki, and T Nagasawa. 2014. Temperature-dependent variation in alternative migratory tactics and its implications for fitness and population dynamics in a salmonid fish. Journal of Animal Ecology. 83: 1268-1278. doi: 10.1111/1365-2656.12240

Morgan, HD, HGE Sutherland, DIK Martin, and E Whitelaw. 1999. Epigenetic inheritance at the agouti locus in the mouse. Nature Genetics. 23(3): 314-318.

Nichols, KM, KW Broman, K Sundin, JM Young, PA Wheeler, GH Thorgaard. 2007.

Quantitative trait loci $\mathrm{x}$ maternal cytoplasmic environment interaction for development rate in Oncorhynchus mykiss. Genetics. 175: 335- 347.

North, JA, RA Farr, and P Vescei. 2002. A comparison of meristic and morphometric characters of green sturgeon Acipencermedirostris. Journal of Applied Ichthyology. 18: 234-239.

O’Malley, KG, DP Jacobson, R Kurth, AJ Dill, and MA Banks. 2013. Adaptive genetic markers discriminate migratory runs of Chinook salmon (Oncorhynchus tshawytscha) amid continued gene flow. Evolutionary Applications. 6(8): 1184-1194.

Ostergren, J, J Nilsson, H Lundqvist. 2012. Linking genetic assignment tests with telemetry enhances understanding of spawning migration and homing in sea trout Salmo trutta L. Hydrobiologia. 691:123-134 DOI 10.1007/s10750-012-1063-7.

Peakall, R and PE Smouse. 2012. GenAlEx 6.5: genetic analysis in Excel. Population genetic software for teaching and research-an update. Bioinformatics. 28: 2537-2539. 
Pritchard, JK, M Stephens, and P Donnelly. 2000. Inference of Population Structure Using Multilocus Genotype Data. Genetics. 155: 945-959.

Pritchard, JK, and A DiRienzo. 2010. Adaptation - not by sweeps alone. Genetics: Nature Reviews. 11: 665-667.

Pujolar, JM, MW Jacobsen, TD Als, J Frydenberg, K Munch, B Jonsson, JB Jian, L Cheng, GE Maes, L Bernatchez, and MM Hansen. 2014. Genome-wide single-generation signatures of local selection in the panmictic European eel. Molecular Ecology. 23: 2514-2528.

Pulido, F, P Berthold, and AJ Van Noordwijk. 1996. Frequency of migrants and migratory activity are genetically correlated in a bird population: Evolutionary implications. Proceedings of the National Academy of Sciences. 93: 14642-14647.

Raymond, M, and F Rousset. 1995. GENEPOP (Version 1.2): Population genetics software for exact tests and ecumenicism. Journal of Heredity. 86(3): 248-249.

Rice, WR. 1989. Analyzing tables of statistical tests. Evolution. 43: 223-225.

Richards, EJ. 2012. Natural epigenetic variation in plant species: a view from the field. Current Opinions in Plant Biology. 14:204-9.

Ruban, GI. 1989. Clinical variation of morphological characters in the Siberian sturgeon, Acipenser baerii, of the Lena Basin. Journal of Ichthyology. 29: 48-55.

Ruban, GI, and LI Sokolov. 1986. Morphological variability of Siberian sturgeon, Acipenser baerii, in the Lena River in relation with its culture in warm water. Journal of Ichthyology. 26: 88-94.

Quinn, TP, and DJ Adams. 1996. Environmental changes affecting the migratory timing of American shad and sockeye salmon. Ecology. 77: 1151-1162.

Schrey, AW, CAC Coon, MT Grispo, M Awad, T Imboma, ED McCoy, HR Mushinsky, CL Richards, and LB Martin. 2012. Epigenetic Variation May Compensate for Decreased Genetic Variation with Introductions: A Case Study Using House Sparrows (Passer domesticus) on Two Continents. Genetics Research International. Article ID 979751: 1-7.

Schrey, AW, M Alvarez, CM Foust, HJ Kilvitis, JD Lee, AL Liebl, LB Martin, CL Richards, and M Robertson. 2013. Ecological Epigenetics: Beyond MS-AFLP. Integrations of Comparative Biology. doi: 10.1093/icb/ict012.

Schwab, DJ, AE Clites. 1986: The effect of wind-induced circulation on retention time in Lake St. Clair. Proceedings of 29th Conference of Great Lakes Research, The International Association for Great Lakes Research. 
Seeb, LW, JE Seeb, C Habicht, EV Farley Jr., and FM Utter. 2011. Single-nucleotide polymorphic genotypes reveal patterns of early juvenile migration of Sockeye Salmon in the eastern Bering Sea. Transactions of the American Fisheries Society. 140: 734-748.

Sloat, MR, DJ Fraser, JB Dunham, JA Falke, CE Jordan, JR McMillan, HA Ohms. 2014. Ecological and evolutionary patterns of freshwater maturation in Pacific and Atlantic salmonines. Reviews in Fish Biology and Fisheries. 24: 689-707.

Solem, Ø, and OK Berg. 2011. Morphological differences in parr of Atlantic salmon Salmo salar from three regions in Norway. Journal of Fisheries Biology. 78: 1451-1469.

Thomas, MV, and RC Haas. 2002. Abundance, age structure, and spatial distribution of lake sturgeon (Acipenser fulvescens) in the St. Clair System. Journal of Applied Ichthyology. 18: 495501 .

Tucker, S, M Trudel, DW Welch, JR Candy, JFT Morris, ME Thiess, C Wallace, and TD Beacham. 2012. Annual coastal migration of juvenile Chinook Salmon: static stock-specific patterns in a highly dynamic ocean. Marine Ecology Progress Series. 449: 245-262.

Vasil'eva, ED. 2009. Morphological and morphometric characters in sturgeon taxonomy and phylogeny. In: Carmona, R, A Domezain, M Garc' 1a-Gallego, JA Hernando, F Rodriguez, M Ruiz-Rejon. (Eds): Biology, Conservation and Sustainable Development of Sturgeons, vol. 1, pp. 51-61. Springer, Media, B.V., Berlin, Heidelberg.

Walsh, MG, MB Bain, JRT Squiers, JR Waldman, and I Wirgin. 2001. Morphological and genetic variation among short- nose sturgeon Acipenser brevirostrum from adjacent and distant rivers. Estuaries. 24: 41-48.

Weir, B, and C Cockerham. 1984. Estimating F-statistics for the analysis of population structure. Evolution. 38: 1358-1370.

Welsh, AB, and B May. 2006. Development and standardization of disomic microsatellite markers for lake sturgeon genetic studies. Journal of Applied Ichthyology. 22: 337-344.

Wills, PS, RJ Sheehan, R Heidinger, BL Sloss, and R Clevenstine. 2002. Differentiation of pallid sturgeon and shovelnose sturgeon using an index based on meristics and morphometrics. American Fisheries Society Symposium. 28: 249-258.

Wolff, GL, RL Kodell, SR Moore, and CA Cooney. 1998. Maternal epigenetics and methyl supplements affect agouti gene expression in Avy/a mice. FASEB Journal. 12(11): 949-57.

Zelditch, ML, DL Swiderski, HD Sheets, and WL Fink. 2004. Geometric Morphometrics for Biologists: a Primer. Elsevier Academic Press, San Diego, California.

Zilberman, D, and S Henikoff. 2007. Genome-wide analysis of DNA methylation patterns. Development. 134:3959-65. 


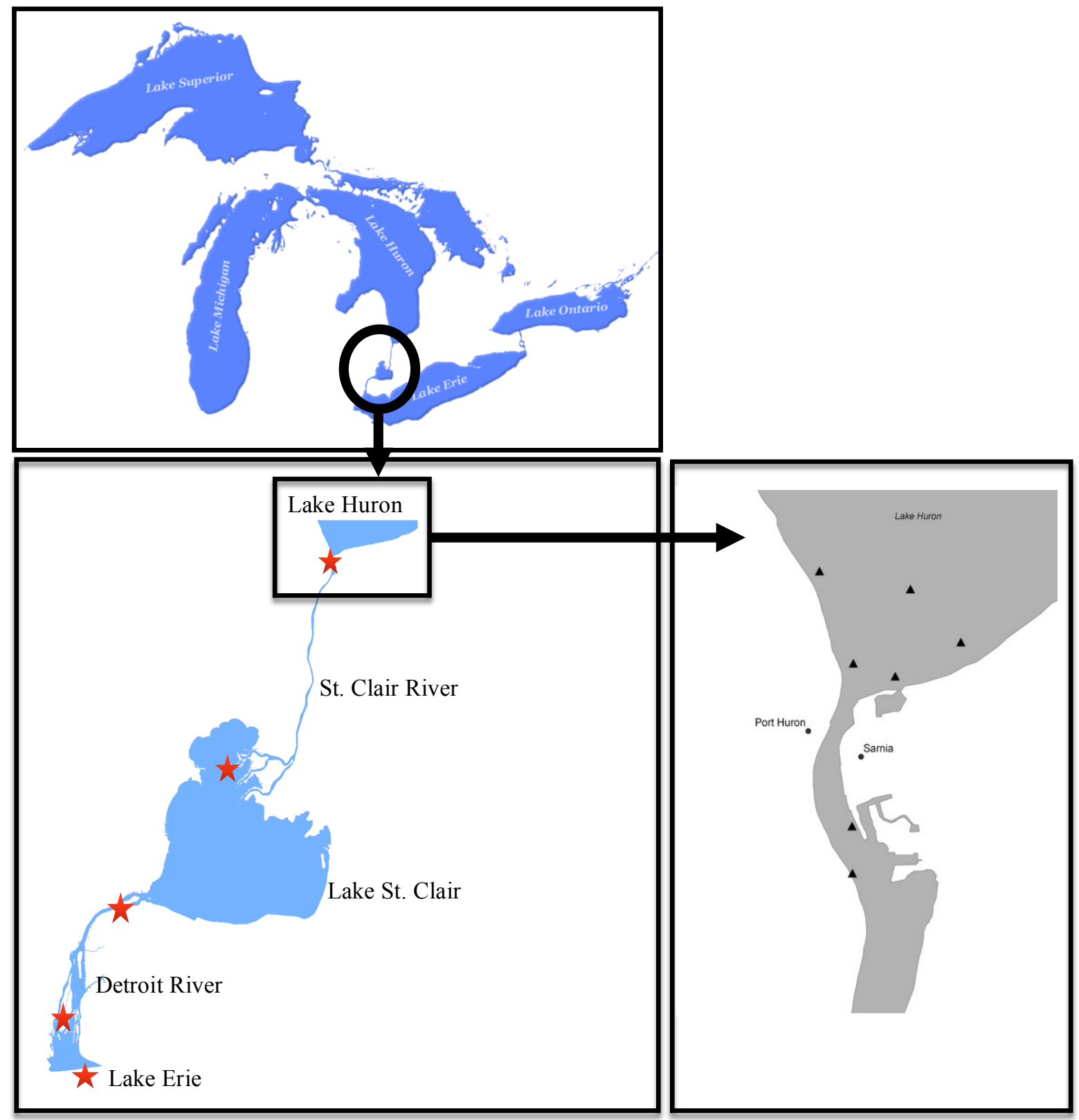

FIGURE 3.1

The St. Clair-Detroit River System (SCDRS), which is part of the Great Lakes, was chosen as the study site. The system includes Lake Huron, the St. Clair River, Lake St. Clair, the Detroit River, and Lake Erie. There are 5 receiver arrays, denoted by red stars in the map of the SCDRS. An enlarged view of the Upper St. Clair receiver array shows the layout of receivers, denoted by black triangles. 


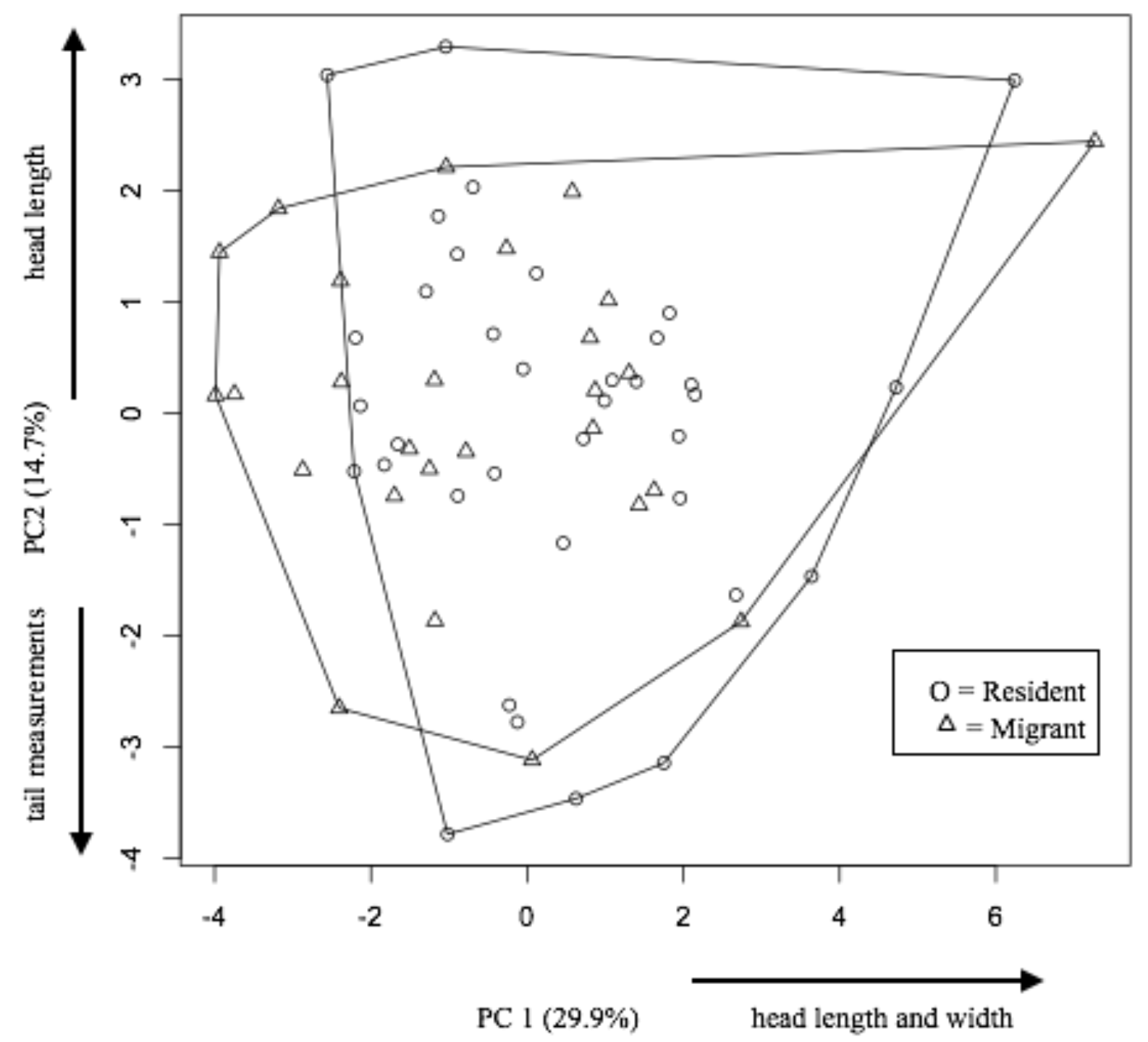

FIGURE 3.2

Scatterplot of principal component scores one and two from principal component analysis performed on morphological measurements taken from 63 fish. Residents are depicted as circles. Migrants are depicted as triangles. The The PCA does not support the hypothesis that there are morphological differences between migratory phenotypes. Migratory phenotypes are not differentiated on the scatterplot. 


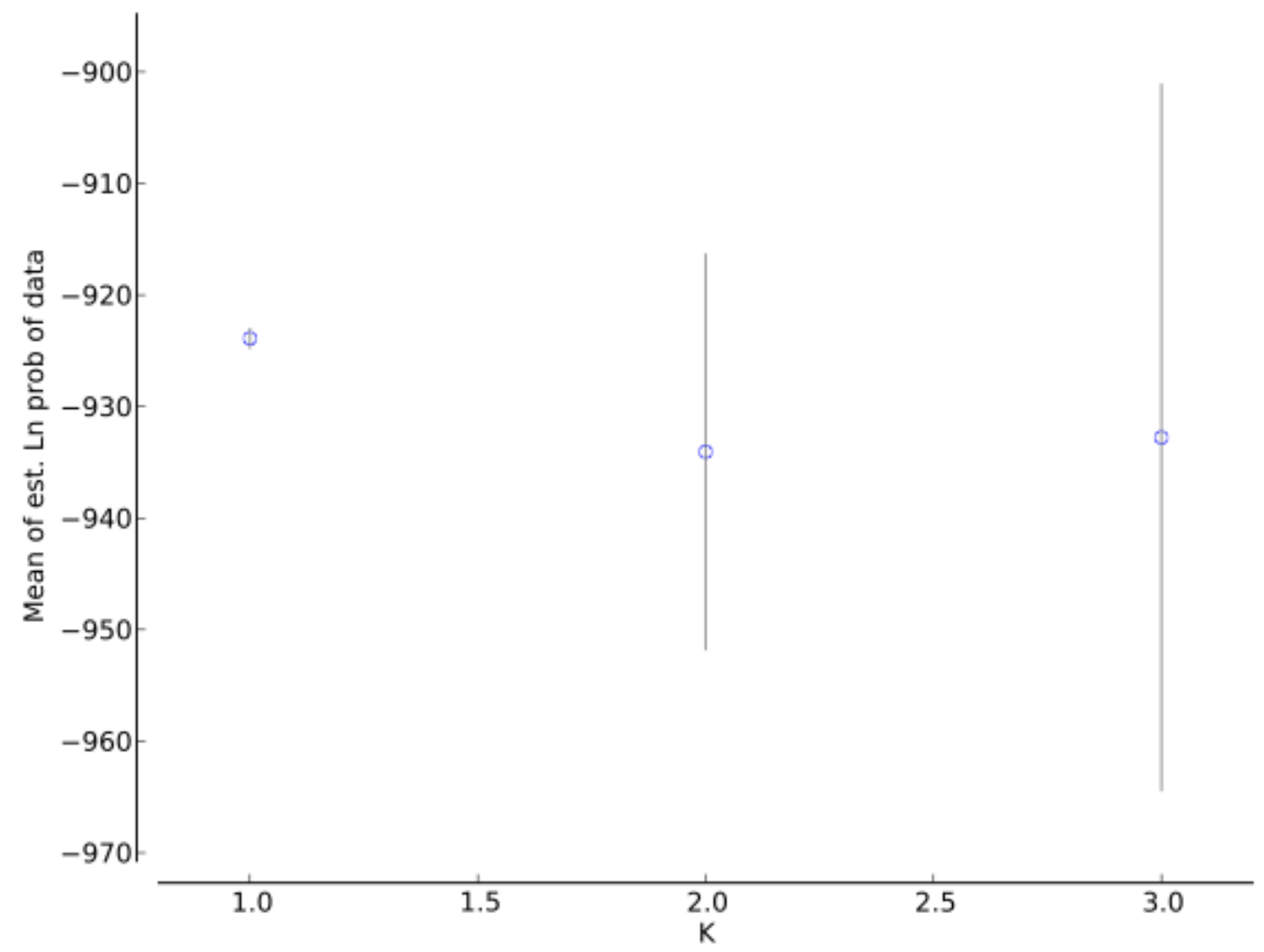

\section{FIGURE 3.3}

These results were generated using a Bayesian approach as implemented in the software program, STRUCTURE. The natural-log likelihood values were plotted against possible values of K. Values of K were tested for 1-3 and the most likely value was chosen based on the highest likelihood and lowest variation. The most likely number of populations is one. 


\begin{tabular}{|c|c|c|c|c|c|c|c|}
\hline Fish ID & Length & Weight & Sex & Corridor & $\begin{array}{c}\text { Lake } \\
\text { Huron }\end{array}$ & Phenotype & Analyses \\
\hline 25161 & 1.404 & 16 & $\mathrm{M}$ & 1 & 0 & Resident & 3 \\
\hline 25162 & 1.51 & 10 & $\mathrm{M}$ & 1 & 0 & Resident & $1,2,3$ \\
\hline 25163 & 1.498 & 22 & $\mathrm{M}$ & 0.06 & 0.94 & Migrant & $1,2,3$ \\
\hline 25164 & 1.749 & 41 & $\mathrm{~F}$ & 0.06 & 0.94 & Migrant & $1,2,3$ \\
\hline 25166 & 1.226 & 12 & $\mathrm{M}$ & 1 & 0 & Resident & 3 \\
\hline 25168 & 1.621 & 27.5 & $\mathrm{~F}$ & 1 & 0 & Resident & $1,2,3$ \\
\hline 25170 & 1.552 & 27 & $\mathrm{U}$ & 0.3 & 0.7 & Migrant & 3 \\
\hline 25185 & 1.48 & 22 & $\mathrm{~F}$ & 1 & 0 & Resident & $1,2,3$ \\
\hline 25186 & 1.236 & 13 & $\mathrm{M}$ & 0.98 & 0.02 & Resident & 3 \\
\hline 25187 & 1.496 & 24 & $\mathrm{M}$ & 1 & 0 & Migrant & 3 \\
\hline 25188 & 1.301 & 15 & $\mathrm{M}$ & 0.01 & 0.99 & Migrant & $1,2,3$ \\
\hline 25190 & 1.374 & 14 & $\mathrm{U}$ & 0.09 & 0.91 & Migrant & $1,2,3$ \\
\hline 25193 & 1.449 & 17 & $\mathrm{M}$ & 0 & 1 & Migrant & $1,2,3$ \\
\hline 25195 & 1.42 & 17 & $\mathrm{M}$ & 0.99 & 0.01 & Resident & 3 \\
\hline 25197 & 1.452 & 20.5 & $\mathrm{M}$ & 0.26 & 0.74 & Migrant & 3 \\
\hline 25198 & 1.506 & 21 & $\mathrm{M}$ & 0.06 & 0.94 & Migrant & $1,2,3$ \\
\hline 25199 & 1.315 & 15 & $\mathrm{M}$ & 0.01 & 0.99 & Migrant & $1,2,3$ \\
\hline 25200 & 1.5 & 19.5 & $\mathrm{M}$ & 0.8 & 0.2 & Resident & 3 \\
\hline 25201 & 1.589 & 22 & $\mathrm{M}$ & 1 & 0 & Resident & $1,2,3$ \\
\hline 25202 & 1.407 & 16 & $\mathrm{M}$ & 0.06 & 0.94 & Migrant & 3 \\
\hline 25203 & 1.553 & 25 & $\mathrm{M}$ & 1 & 0 & Resident & $1,2,3$ \\
\hline 25204 & 1.3 & 15 & $\mathrm{U}$ & 0.99 & 0.01 & Resident & 3 \\
\hline 25205 & 1.498 & 27 & $\mathrm{U}$ & 0.02 & 0.98 & Migrant & $1,2,3$ \\
\hline 25206 & 1.564 & 22.5 & $\mathrm{M}$ & 0.08 & 0.92 & Migrant & $1,2,3$ \\
\hline 25208 & 1.5 & 20.5 & $\mathrm{M}$ & 1 & 0 & Resident & $1,2,3$ \\
\hline 25217 & 1.675 & 48 & $\mathrm{~F}$ & 1 & 0 & Migrant & $1,2,3$ \\
\hline 25218 & 1.614 & 33 & $\mathrm{~F}$ & 0.03 & 0.97 & Migrant & $1,2,3$ \\
\hline 25219 & 1.642 & 33 & $\mathrm{~F}$ & 0.03 & 0.97 & Resident & 3 \\
\hline 25223 & 1.321 & 15 & $\mathrm{M}$ & 1 & 0 & Migrant & $1,2,3$ \\
\hline 25227 & 1.626 & 28 & $\mathrm{M}$ & 1 & 0 & Resident & 3 \\
\hline 25229 & 1.664 & 44 & $\mathrm{~F}$ & 1 & 0 & Resident & 3 \\
\hline 27230 & 1.372 & 14 & $\mathrm{M}$ & 1 & 0 & Resident & 3 \\
\hline 27231 & 1.424 & 24 & $\mathrm{U}$ & 0.99 & 0.01 & Resident & $1,2,3$ \\
\hline 27232 & 1.349 & 18 & $\mathrm{U}$ & 0.09 & 0.91 & Migrant & $1,2,3$ \\
\hline 27233 & 1.674 & 39.5 & $\mathrm{~F}$ & 1 & 0 & Resident & 3 \\
\hline 27234 & 1.412 & 21 & $\mathrm{M}$ & 0.13 & 0.87 & Migrant & $1,2,3$ \\
\hline 27235 & 1.549 & 25 & $\mathrm{U}$ & 0.02 & 0.98 & Migrant & $1,2,3$ \\
\hline 27236 & 1.736 & 35 & $\mathrm{U}$ & 1 & 0 & Resident & $1,2,3$ \\
\hline
\end{tabular}




\begin{tabular}{cccccccc}
27238 & 1.5 & 20 & $\mathrm{M}$ & 0.02 & 0.98 & Migrant & $1,2,3$ \\
27240 & 1.475 & 17 & $\mathrm{M}$ & 1 & 0 & Resident & 3 \\
27241 & 1.552 & 30 & $\mathrm{~F}$ & 1 & 0 & Resident & $1,2,3$ \\
27242 & 1.803 & 25.3 & $\mathrm{~F}$ & 1 & 0 & Resident & $1,2,3$ \\
27245 & 1.24 & 10 & $\mathrm{U}$ & 1 & 0 & Resident & $1,2,3$ \\
27247 & 1.425 & 16 & $\mathrm{M}$ & 1 & 0 & Resident & $1,2,3$ \\
27255 & 1.486 & 19.2 & $\mathrm{M}$ & 0.05 & 0.95 & Migrant & $1,2,3$ \\
27259 & 1.405 & 15.4 & $\mathrm{U}$ & 1 & 0 & Resident & $1,2,3$ \\
27261 & 1.458 & 22.2 & $\mathrm{U}$ & 1 & 0 & Resident & 3 \\
27277 & 1.423 & 17.5 & $\mathrm{M}$ & 0.98 & 0.02 & Resident & $1,2,3$ \\
27279 & 1.525 & 24 & $\mathrm{U}$ & 0.99 & 1 & Resident & $1,2,3$ \\
29348 & 1.388 & 15 & $\mathrm{M}$ & 0 & 1 & Resident & $1,2,3$ \\
29350 & 1.405 & 17 & $\mathrm{M}$ & 0.1 & 0.9 & Migrant & $1,2,3$ \\
29351 & 1.393 & 17 & $\mathrm{M}$ & 0.04 & 0.96 & Migrant & $1,2,3$ \\
29352 & 1.369 & 17.5 & $\mathrm{M}$ & 0.02 & 0.98 & Resident & $1,2,3$ \\
29354 & 1.517 & 26 & $\mathrm{M}$ & 1 & 0 & Resident & 3 \\
29355 & 1.503 & 25 & $\mathrm{M}$ & 1 & 0 & Resident & 3 \\
29356 & 1.476 & 23 & $\mathrm{U}$ & 0.06 & 0.94 & Migrant & $1,2,3$ \\
29357 & 1.462 & 23.5 & $\mathrm{M}$ & 0.37 & 0.63 & Migrant & 3 \\
29358 & 1.74 & 37.5 & $\mathrm{U}$ & 0.79 & 0.21 & Resident & $1,2,3$ \\
29359 & 1.547 & 24.5 & $\mathrm{M}$ & 0.09 & 0.91 & Migrant & $1,2,3$ \\
29366 & 1.365 & 17 & $\mathrm{M}$ & 0.02 & 0.98 & Migrant & $1,2,3$ \\
29368 & 1.584 & 26 & $\mathrm{U}$ & 1 & 0 & Resident & $1,2,3$ \\
31403 & 1.262 & 12 & $\mathrm{U}$ & 1 & 0 & Resident & 3 \\
31405 & 1.631 & 25.6 & $\mathrm{U}$ & 1 & 0 & Resident & 3 \\
\hline & & & & & & & \\
\hline
\end{tabular}

TABLE 2.1

This table provides the identification number, length $(\mathrm{m})$, weight $(\mathrm{kg})$ and sex $(\mathrm{M}=\mathrm{male}$, $\mathrm{F}=$ female, $\mathrm{U}=$ uknown) for fish used in this study. Habitat use is expressed in proportion for the corridor (St. Clair River, Lake St. Clair, and Detroit River) and Lake Huron. The "Analyses" column details which analyses were performed on each fish. $1=$ MS-AFLPs, $2=$ microsatellite genotyping, $3=$ morphometrics. 


\begin{tabular}{|c|c|c|}
\hline Variable & $\mathrm{PC} 1$ & $\mathrm{PC} 2$ \\
\hline Eigenvalue & 4.99 & 2.5 \\
\hline$\%$ variation & $29.40 \%$ & $14.70 \%$ \\
\hline Barbels to mouth (v) & 0.74 & 0.58 \\
\hline Gape (v) & 0.74 & 0.04 \\
\hline Snout Length (v) & 0.73 & 0.59 \\
\hline Rostrum to operculum (v) & 0.79 & 0.48 \\
\hline Pectoral fin (v) & 0.38 & -0.2 \\
\hline Width between eyes (d) & 0.76 & -0.37 \\
\hline Width between opercula (d) & 0.73 & -0.27 \\
\hline Rostrum to operculum (d) & 0.59 & -0.14 \\
\hline Pectoral fin (d) & -0.12 & -0.32 \\
\hline Rostrum to nare (I) & 0.25 & 0.25 \\
\hline Nare to eye (I) & 0.38 & 0.25 \\
\hline Eye diameter (l) & 0.32 & -0.05 \\
\hline Pectoral fin (l) & 0.35 & -0.11 \\
\hline Total length (l) & 0.45 & -0.1 \\
\hline Upper tail fin (l) & 0.37 & -0.62 \\
\hline Lower tail fin (l) & 0.38 & -0.57 \\
\hline Peduncle widthv(l) & 0.46 & -0.59 \\
\hline Dorsal fin (l) & 0.3 & -0.25 \\
\hline
\end{tabular}

TABLE 3.2

Results of the principal component analysis on morphological data. Eigenvalues, \% variation explained and factor loadings of the 18 measurements for the first two principal components are provided. The letters in parentheses represent the view from which the photograph was taken ( $v=$ ventral, $d=$ dorsal, l=lateral). 


\begin{tabular}{ccccc}
\hline Source & $\begin{array}{c}\text { Degrees } \\
\text { of } \\
\text { Freedom }\end{array}$ & $\begin{array}{c}\text { Sum of } \\
\text { Squares }\end{array}$ & $\begin{array}{c}\text { Mean } \\
\text { Square }\end{array}$ & $\begin{array}{c}\text { Estimated } \\
\text { Variance }\end{array}$ \\
\hline $\begin{array}{c}\text { Among } \\
\text { Populations }\end{array}$ & 1 & 35.453 & 35.453 & 1.562 \\
$\begin{array}{c}\text { Within } \\
\text { Populations }\end{array}$ & 40 & 118.261 & 2.957 & 2.957 \\
Total & 41 & 153.714 & & 4.518 \\
\hline
\end{tabular}

\section{TABLE 3.3}

Summary statistics AMOVA table from the analysis of total restriction sites (81) analyzed between migratory and resident phenotypes. The AMOVA was performed using GenALEx 6.5 with 9999 permutations and an alpha of $\leq 0.05$. The AMOVA showed that the migratory phenotypes are differentially methylated. 


\begin{tabular}{cc} 
Restriction Site & P-value \\
\hline 104 & 0.029 \\
118 & 0.001 \\
121 & 0.001 \\
122 & 0.001 \\
129 & 0.002 \\
165 & 0.001 \\
176 & 0.001 \\
206 & 0.001 \\
209 & 0.006 \\
217 & 0.001 \\
227 & 0.001 \\
267 & 0.001 \\
308 & 0.005 \\
\hline All sites & 0.001
\end{tabular}

\section{TABLE 3.4}

The AMOVA was performed using GenALEx 6.5 with 9999 permutations and was performed on individual loci and all loci. Loci reported in this table are statistically significant at an alpha of $<0.05$. The AMOVA on all loci showed that the migratory phenotypes are differentially methylated. When analyzed individually, 13 loci were statistically significant. 